\title{
Crystal Structure, Spectral investigations, DFT and Antimicrobial activity of Brucinium Benzilate (BBA)
}

Karnan Chandran ( $\nabla$ c.karnan@yahoo.com )

Dr MGR Educational and Research Institute https://orcid.org/0000-0003-3435-6497

Nagaraja Karachalacherevu Seetharamiah

Dr MGR Educational and Research Institute

Manivannan Sambanthan

Dr MGR Educational and Research Institute

Manikandan Anandhan

SSN College of Engineering: Sri Sivasubramaniya Nadar College of Engineering

Ragavendran Venkatesan

Sri Chandrasekharendra Swaraswathi Viswa Maha Vidyalaya

\section{Research Article}

Keywords: Brucinium Benzilate, Crystal Structure, DFT, Spectroscopy, Antimicrobial Properties

Posted Date: April 8th, 2021

DOl: https://doi.org/10.21203/rs.3.rs-343924/v1

License: (c) (1) This work is licensed under a Creative Commons Attribution 4.0 International License. Read Full License

Version of Record: A version of this preprint was published at Journal of Molecular Modeling on July 9th, 2021. See the published version at https://doi.org/10.1007/s00894-021-04842-w. 


\section{Crystal Structure, Spectral investigations, DFT and Antimicrobial activity of Brucinium Benzilate (BBA)}

Karnan Chandran $^{\mathrm{a} *}$, Nagaraja Karachalacherevu Seetharamiah ${ }^{\mathrm{b}}$, Manivannan Sambanthan ${ }^{\mathrm{c}}$, Manikandan Anandhan ${ }^{\mathrm{d}}$ and Ragavendran Venkatesan ${ }^{\mathrm{e}}$

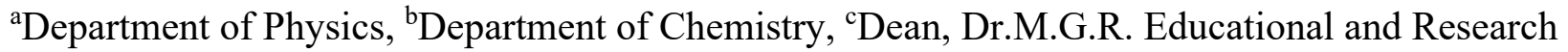
Institute, Chennai 600 095, India.

${ }^{\mathrm{d} S S N}$ Research Centre, SSN College of Engineering, Chennai 603 110, India. eDepartment of Physics, Sri Chandrasekharendra Saraswathi Viswa Mahavidyalaya, Kanchipuram 631 561, India.

*E-Mail: c.karnan@yahoo.com, karnan.phy@drmgrdu.ac.in; +91 9600 097511;

ORCID: 0000-0003-3435-6497 
Abstract: The unreported Brucinium Benzilate (BBA) crystal and hirshfeld surface analysis indicated the influence of intramolecular hydrogen bonding network. The protonation of tertiary nitrogen occurs as it is most basic. The protonated $\mathrm{N}-\mathrm{H}^{+}$proton was observed at $7.08 \mathrm{ppm}$ and the benzilate carbon $\mathrm{COO}^{-}$at $178.41 \mathrm{ppm}$. Molecular electrostatic potential (MEP) studies indicated the electron-rich and electron-deficient sites in the molecule for understanding BBA interaction with an enzyme. Frontier molecular orbital (FMO) studies indicated that it is thermodynamically stable and HOMO-LUMO energy gap was found to be $4.454 \mathrm{eV}$. The highest interaction as the energy $(322.86 \mathrm{kcal} / \mathrm{mol})$ between tertiary ammonium $\mathrm{N}(\mathrm{LP})$ and $\mathrm{H}^{+}$. The compound showed the inhibition of Bacillus cereus and Salmonella typhimurium bacteria. ADMET properties indicated that BBA has drug characteristics in binding plasma protein.

Keywords: Brucinium Benzilate, Crystal Structure, DFT, Spectroscopy, Antimicrobial Properties.

\section{Graphical Abstract}

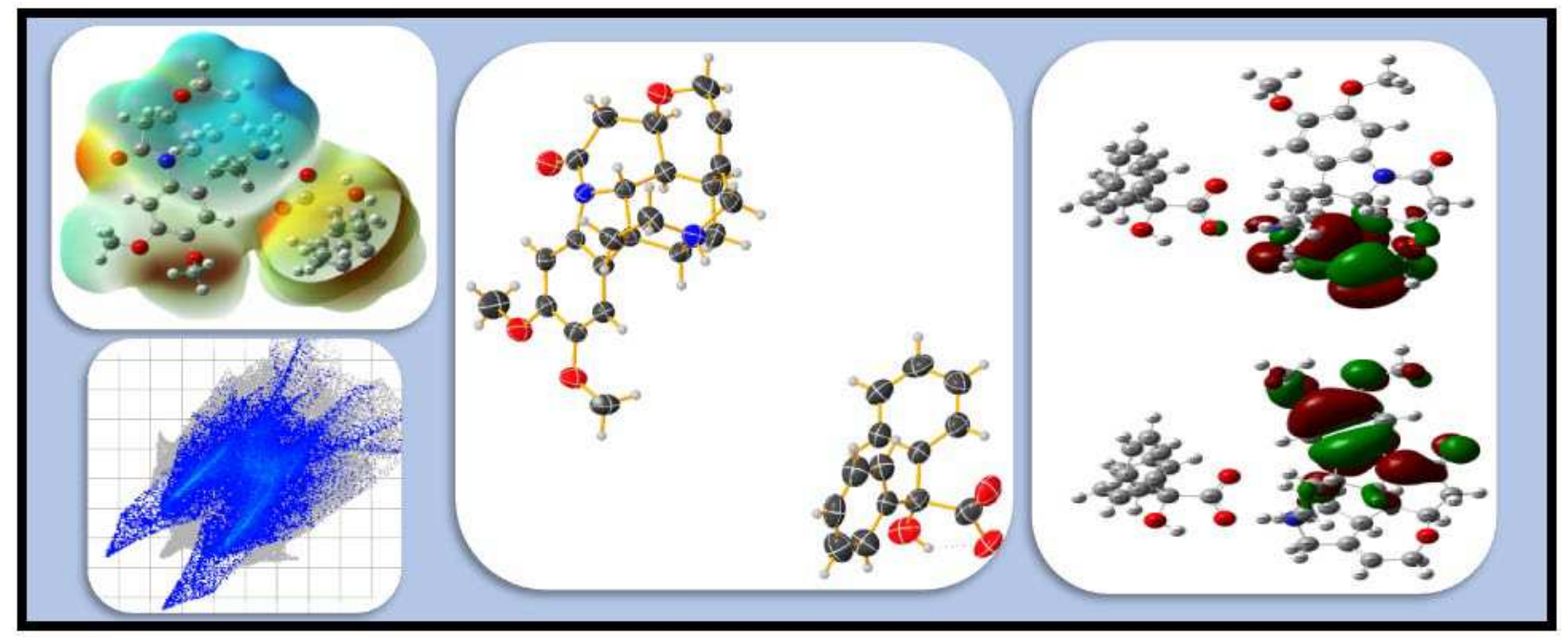




\section{Introduction}

Synthesis and design of multicomponent organic crystals such as hydrogen-bonded molecular complexes[1], salts and solvates play an important role in the field of crystal engineering and pharmaceutical chemistry [2]. The formation of salt is the primary solidstate approach used to overcome the inferior physical properties of active pharmaceutical ingredients (APIs)[3]'[4]. Pharmaceutical cocrystals for physical property optimization have been described for several drugs through hydrogen bonding[5],[6]. Brucine, an alkaloid, isolated from seeds of strychnos nux-vomica[7], has antitumor, antiproliferative[8], cytotoxic and antiangiogenic activity[9]. Brucine can be protonated when treated with organic acids to form salts. Brucinium-3,5-dinitrobenzoate methanol solvates[10]'[11], Brucinium hydrogen fumarate sesquihydrate, brucinium hydrogen maleate[12], Brucine two solvates[13], brucinium dihydrogen citrate trihydrate[14], brucinium $N$-phthaloyl- $\beta$-alaninate hydrate[15], pseudopolymorphism in brucine-water hydrate[16] and isomorphous brucinium - 4-nitrobenzoates[17] have been reported.

Recently, benzilic acid derivatives were recognized as a potent antimicrobial agent with good activity range[18]. Benzilic acid shows multi-use such as polymers, medicine and analytical agent[19]. Brucine and benzilic acid exhibit a variety of medicinal uses. In the present study single crystal XRD of brucinium benzilate and characterization by ATR-IR, FT-Raman ${ }^{1} \mathrm{H} N M R$ and ${ }^{13} \mathrm{C}$ NMR. DFT calculations were performed using the crystallography information and the theoretical results were compared with the vibrational experimental results. Computational analyses like HOMO-LUMO, Natural bond order (NBO) and Molecular electrostatic potential (MEP) analysis were performed to know about molecular properties. ADMET properties of the material are reported to throw light on its biomedical applications. 


\section{Experimental Section}

\subsection{Synthesis of Brucinium benzilate}

Brucine (AR, LOBA) and benzilic acid (AR, Merck) were taken in equimolar ratio to prepare brucinium benzilate solution in ethanol. The solution was filtered using Whatman filter paper twice and the filtrate was allowed to crystallize. Repeated recrystallization in ethanol yielded the quality crystals after 24 days.

\subsection{Single crystal X-ray diffraction.}

The structure determination (CCDC NO: 1966353) was done by the direct method using SHELXT-2014/4[20] and refined using full-matrix least-squares on $\mathrm{F}^{2}$ method using SHELXL2018/3[21]. Multi-scan SADABS[22] was used to perform area-detector scaling and absorption corrections. Anisotropic displacement parameters were assigned to locate non-hydrogen atoms.

\subsection{Spectroscopy}

ATR studies were done using Perkin Elmer Spectrum one. FT-IR Spectrometer. The FT Raman spectrum was recorded in the spectral range of $4000-50 \mathrm{~cm}^{-1}$ using Bruker RFS 27 FT Raman spectrometer. NMR studies were done using the AVANCE III 500 NMR spectrometer.

\subsection{Computational details.}

Quantum chemical calculations were performed on the title molecule by applying DFT method using the Gaussian 09 program suite[23] at the Becke-3-Lee-Yang-Par (B3LYP) level[24],[25] combined with the standard $6-31 \mathrm{G}^{* *}$ basis set. During the optimization procedure, all parameters were allowed to relax to obtain a stable structure with minimum 
energy. The minimum global energy of the title compound was ascertained from the structure optimization procedure. The Natural bonding orbital (NBO) analysis was performed using NBO 5.0 program[26] as implemented in the Gaussian 09 package at DFT/B3LYP level. The hyperconjugation and the interaction energy within the molecule were deduced from the second-order perturbation approach[27-29].

\section{Results and Discussion}

\subsection{Crystallographic and structural details.}

BBA crystallized (Table 1) in an ionic form by forming protonated brucinium cation and deprotonated benzilate anion (Fig. 1). Brucinium cation consists of seven rings in the structure with one aromatic ring consisting of two methoxy groups. The $\mathrm{O} 5$ and $\mathrm{O} 7$ methoxy groups formed a torsional angle $\mathrm{C}(17)-\mathrm{C}(18)-\mathrm{O}(5)-\mathrm{C}(15)=177.0(3)^{\circ}, \mathrm{C}(18)-\mathrm{C}(17)-\mathrm{O}(7)-\mathrm{C}(16)=-170.8(3)^{\circ}$ which indicated that $\mathrm{O}(5)-\mathrm{CH}_{3}$ is above the plane of the benzene ring and $\mathrm{O}(7)-\mathrm{CH}_{3}$ is below the plane to avoid steric hindrance. Brucinium ion consists of indoline ring with $\mathrm{sp}^{2}$ hybridized nitrogen atom forming the torsional angles, $\mathrm{N}(1)-\mathrm{C}(21)-\mathrm{C}(22)-\mathrm{C}(17)=174.2(3)^{\circ}, \mathrm{N}(1)-\mathrm{C}(32)-$ $\mathrm{C}(33)-\mathrm{C}(34)=38.4(4)^{\circ}, \mathrm{O}(6)-\mathrm{C}(32)-\mathrm{N}(1)-\mathrm{C}(21)=23.8(5)^{\circ} \cdot \mathrm{sp}^{2}$ hybridized $\mathrm{N} 2$ atom is converted to $\mathrm{sp}^{3}$ hybridization due to protonation. Heterocyclic ring C2, C28, C29, C25, C24, and N2 adopts a boat conformation. The oxacyclohexene is steeply inclined to plane of a benzene ring and forming a bond angle with $\mathrm{O} 4$ atom $\mathrm{C}(34)-\mathrm{O}(4)-\mathrm{C}(35)=115.7(3)^{\circ}$. The $\mathrm{sp}^{3}$ hybridized $\mathrm{N} 2$ atom forming bond angle $\mathrm{C}(27)-\mathrm{N}(2)-\mathrm{H}(2 \mathrm{~A})=109(2)^{\circ}$. The indoline ring nitrogen atom connected with $\mathrm{C}=\mathrm{O}$ which confirms the amide group and forming bond angle $\mathrm{O}(6)-\mathrm{C}(32)-\mathrm{N}(1)=122.1(3)^{\circ}$. Heterocyclic ring N1, C32, C33, C34, C30 and C37 are in a boat conformation. Benzilate anion consists of hydroxyl, carboxylate and two aromatic rings which are tetrahedral to a $\mathrm{C} 7$ atom forming bond angle $\mathrm{C}(9)-\mathrm{C}(7)-\mathrm{C}(6)=111.9(3)^{\circ}, \mathrm{O}(1)-\mathrm{C}(7)-\mathrm{C}(8)=111.3(16)^{\circ}, \mathrm{C}(9)-\mathrm{C}(7)-\mathrm{C}(8)=$ 
106.2(11) ${ }^{\circ}$ and $\mathrm{C}(6)-\mathrm{C}(7)-\mathrm{C}(8)=102.8(9)^{\circ}$. The benzilate anion consists of disordered over four positions at $\mathrm{C}(8), \mathrm{O}(1), \mathrm{O}(2)$ and $\mathrm{O}(3)$ with chemical occupancies 0.45:0.55 respectively (Fig. S1). A strong intermolecular interaction (Fig. 2) is formed between protonated brucine and deprotonated benzylic acid-forming intermolecular hydrogen bonding interactions such as $\mathrm{N}(2)-\mathrm{H}(2 \mathrm{~A}) \ldots \mathrm{O}\left(2^{\wedge} \mathrm{a}\right)$ and $\mathrm{N}(2)-\mathrm{H}(2 \mathrm{~A}) \ldots \mathrm{O}\left(3^{\wedge} \mathrm{a}\right)$ with symmetry operation $\mathrm{x}-1 / 2,-\mathrm{y}+1 / 2,-$ $\mathrm{z}+2$.

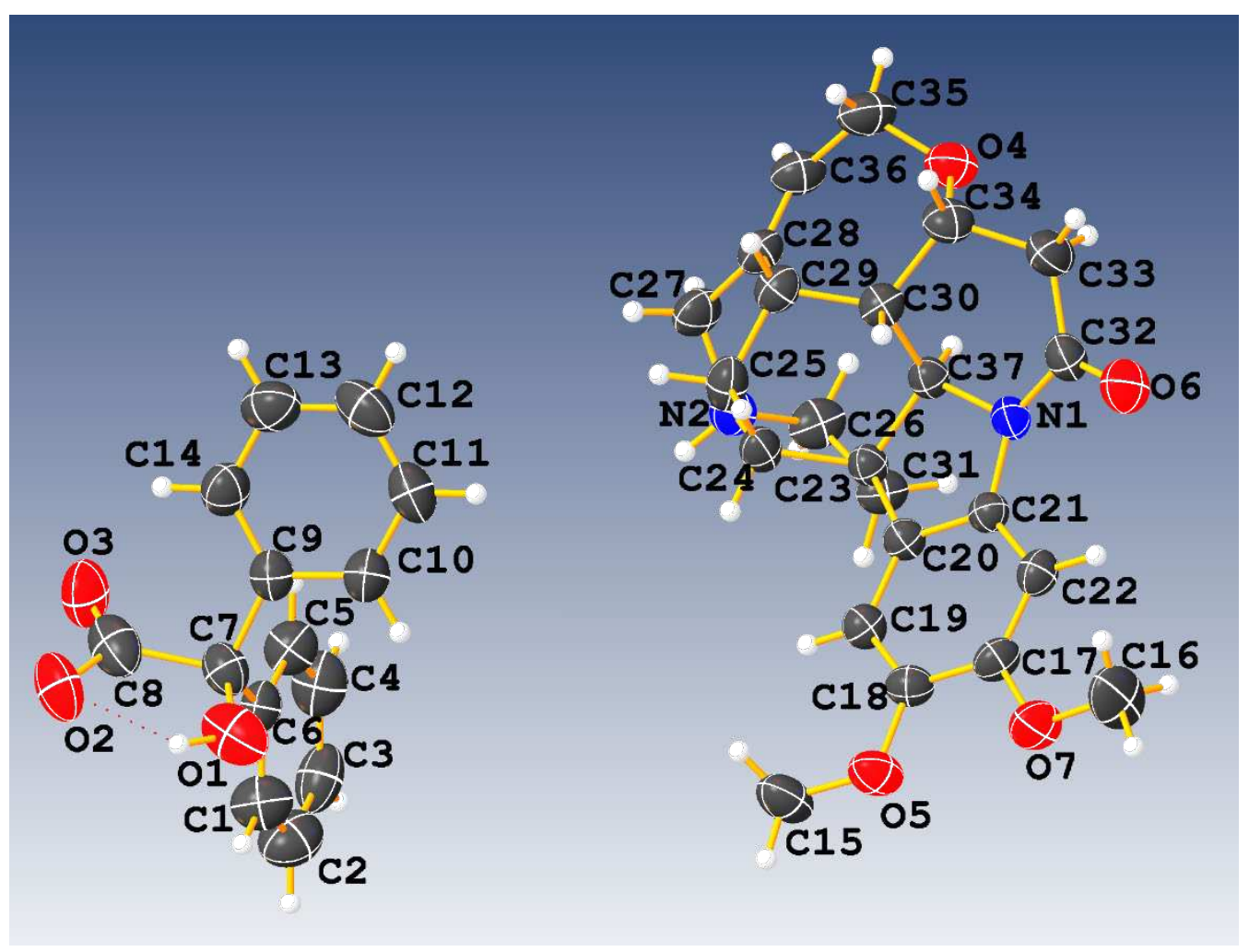

Fig. 1 Ortep view of BBA 


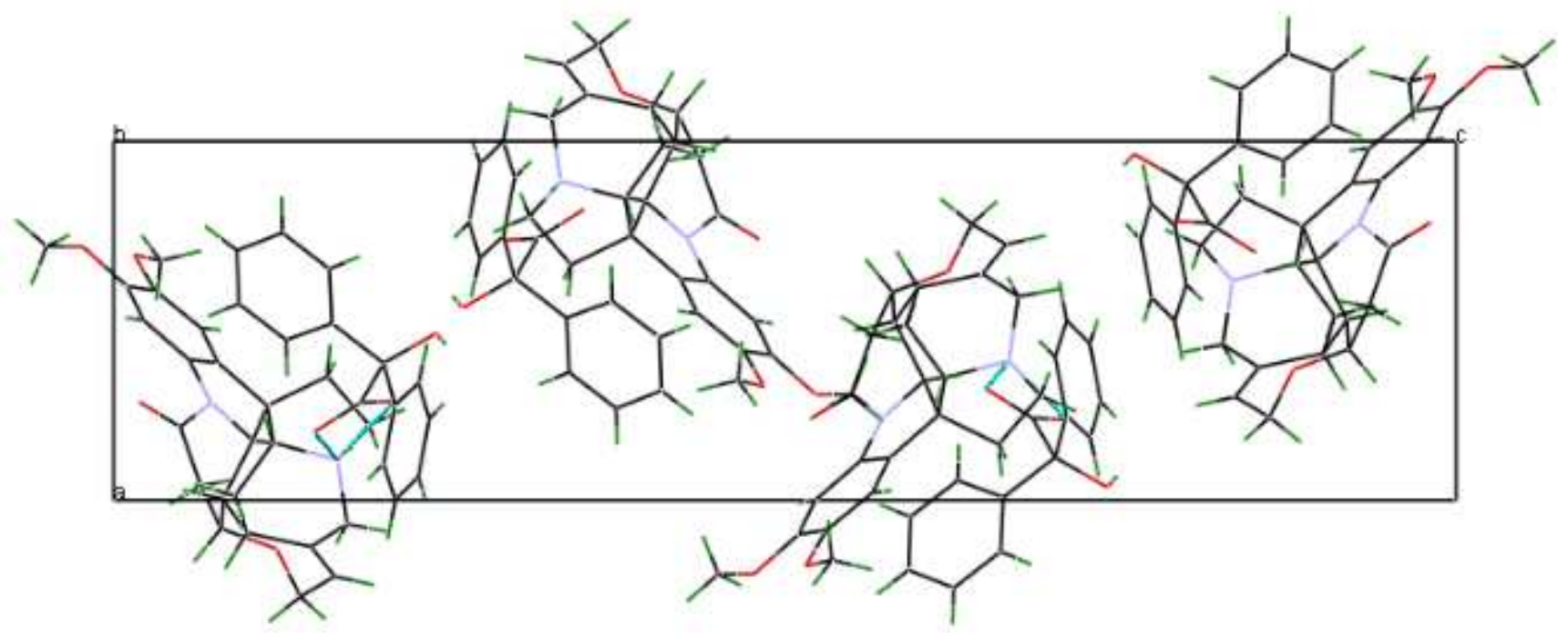

Fig. 2 Molecular packing of BBA

Table 1. Crystal data and data collection parameters for BBA

\begin{tabular}{|l|l|}
\hline Parameters & BBA \\
\hline Molecular formula & C37 H38 N2 O7 \\
\hline Formula weight & 622.69 \\
\hline Crystal system & Orthorhombic \\
\hline Space group & P212121 \\
\hline $\mathrm{a}[\AA]$ & $8.2586(13)$ \\
\hline $\mathrm{b}[\AA]$ & $11.9946(18)$ \\
\hline $\mathrm{c}[\AA]$ & $30.956(5)$ \\
\hline$\left.\alpha=\beta=\gamma{ }^{\circ}\right]$ & 90 \\
\hline $\mathrm{V}\left[\AA^{3}\right]$ & $3066.4(8)$ \\
\hline $\mathrm{Z}$ & 4 \\
\hline$d_{\text {calcd }}\left[\mathrm{Mg} / \mathrm{m}^{3}\right]$ & 1.349 \\
\hline$\mu\left[\mathrm{mm}^{-1}\right]$ & 0.093 \\
\hline $\mathrm{F}(000)$ & 1320 \\
\hline
\end{tabular}




\begin{tabular}{|l|l|}
\hline $2 \theta$ range $\left[^{\circ}\right]$ & 2.552 to 24.995 \\
\hline Independent reflections & $5401[\mathrm{R}($ int $)=0.0632]$ \\
\hline $\mathrm{R} 1, \mathrm{wR} 2[\mathrm{I}>2 \sigma(\mathrm{I})]$ & $0.0371,0.0764$ \\
\hline $\mathrm{R} 1, \mathrm{wR} 2$ (all data) & $0.0616,0.0881$ \\
\hline GOF & 1.059 \\
\hline Largest diff. Peak/hole, $\left[\mathrm{e} . \AA^{-3}\right]$ & 0.147 and -0.146 \\
\hline
\end{tabular}

\subsection{Optimized Structure}

Structure optimization is performed on BBA crystal structure to calculate theoretically the most stable geometry, bond lengths and bond angles using DFT/B3LYP at 6-31G** level. The selected bond lengths and bond angle values were compared with XRD data in (Table S1). Small variations were observed between the XRD and its optimized geometry because DFT calculations assume the interactions in a gaseous state. The optimized geometry of the BBA with atom numbering scheme is depicted in Fig. 3. 


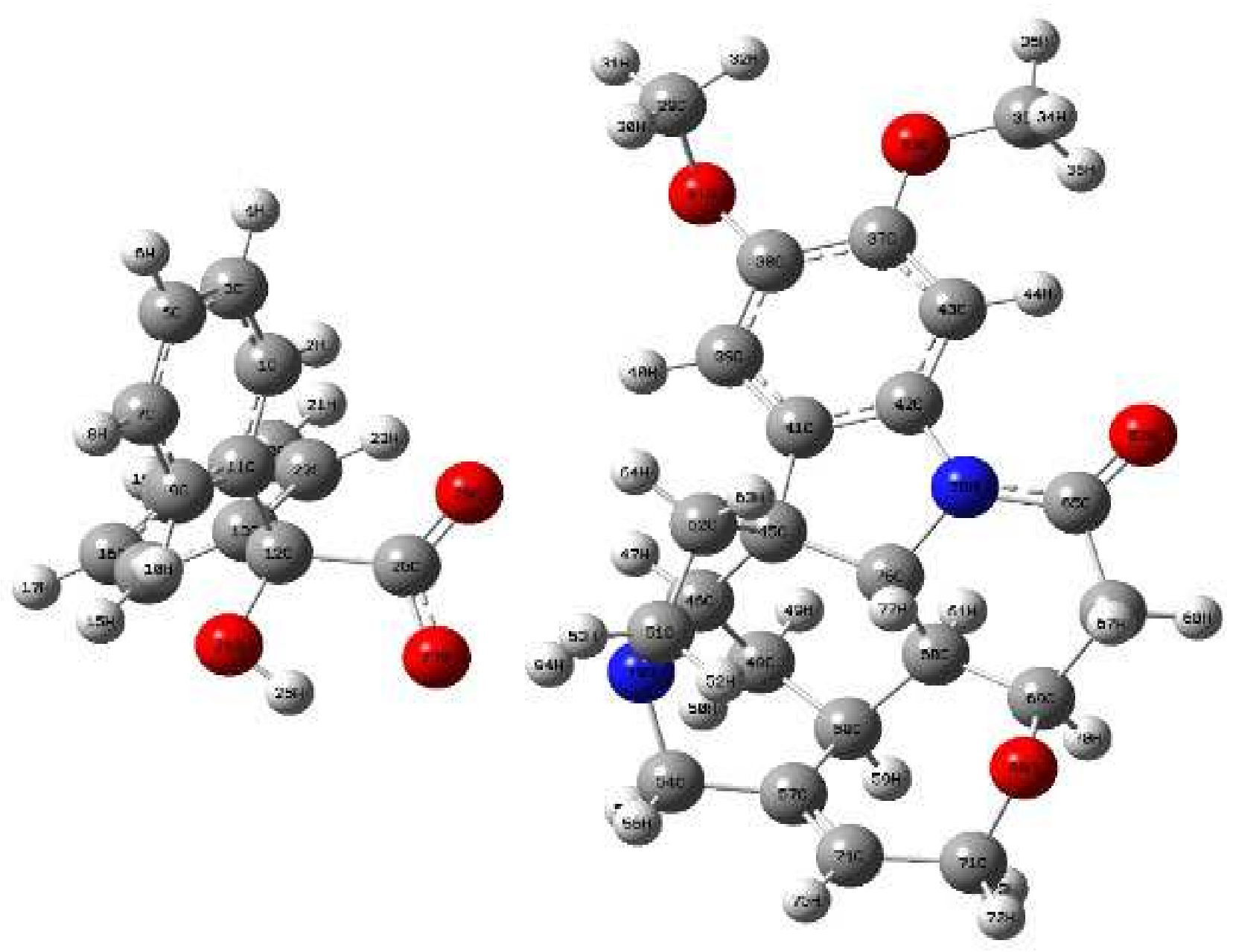

Fig. 3 Optimized geometry of BBA

\subsection{Hirshfeld surface analysis}

The Hirshfeld surface analysis is an essential tool for understanding the interactions[30]. The intermolecular interactions were analyzed by crystal explorer 3.1[31], which produce Hirshfeld surface (Fig. 4) of the compound. The de and di surfaces indicate the hydrogen donor and acceptor interactions through dark red spots. The dnorm red spot indicates the strong interactions on the molecule, weak interactions over the blue region, and white regions indicate no interactions. The fingerprint plots of atom-atom interactions (Fig. 5) indicated that the intermolecular and intramolecular interactions were observed between 
H...H (54.9\%), O...H (24.1\%), C...H (18.3\%), C... (1.8\%) and N...H (0.9\%). The stability of the material was emphasized by strong interactions between carboxylate oxygen of $\mathrm{COO}^{-}$and the hydrogen of $\mathrm{NH}^{+}$of brucinium ion.

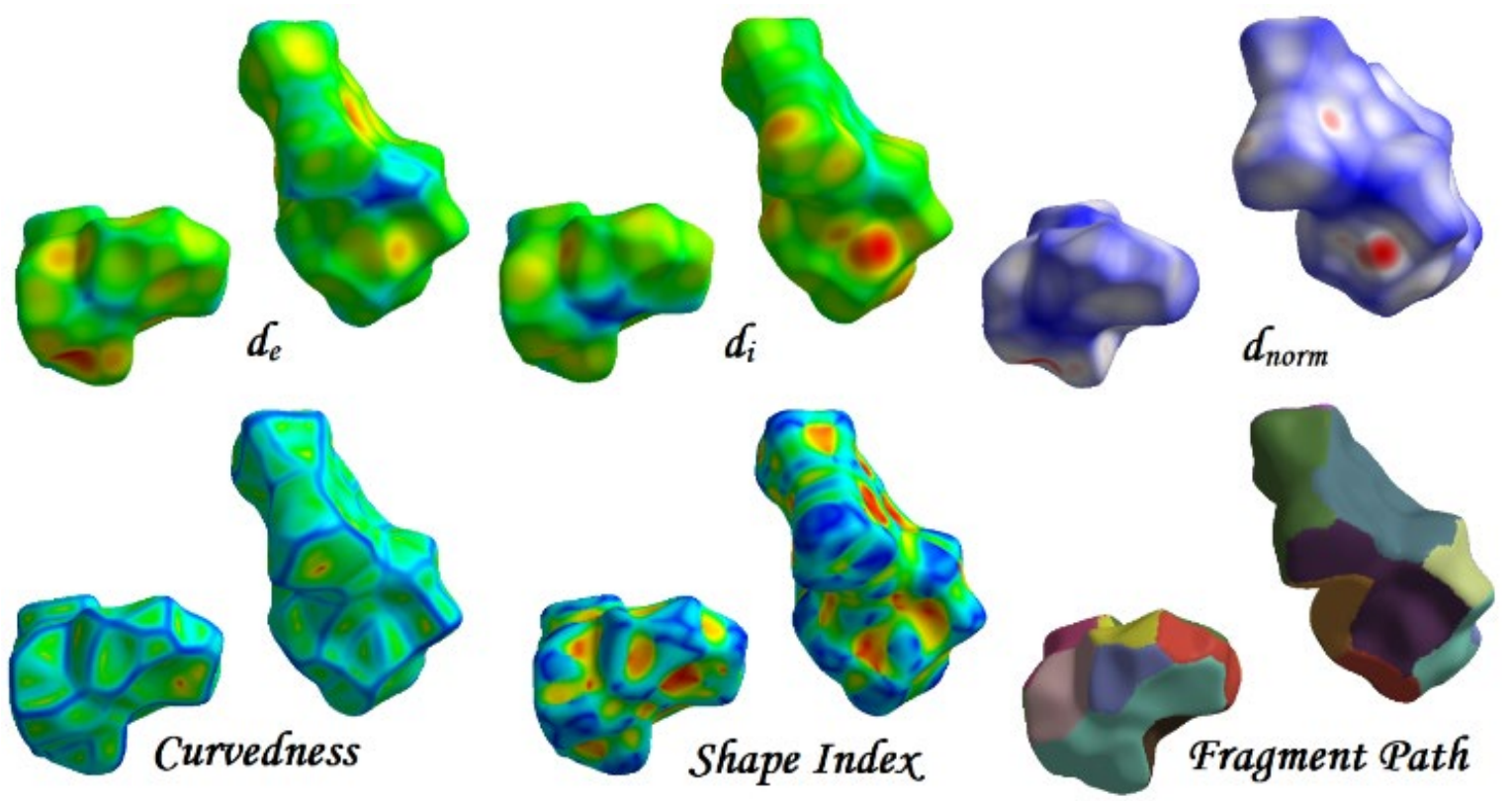

Fig. 4 Hirshfeld surface analysis of brucinium benzilate 

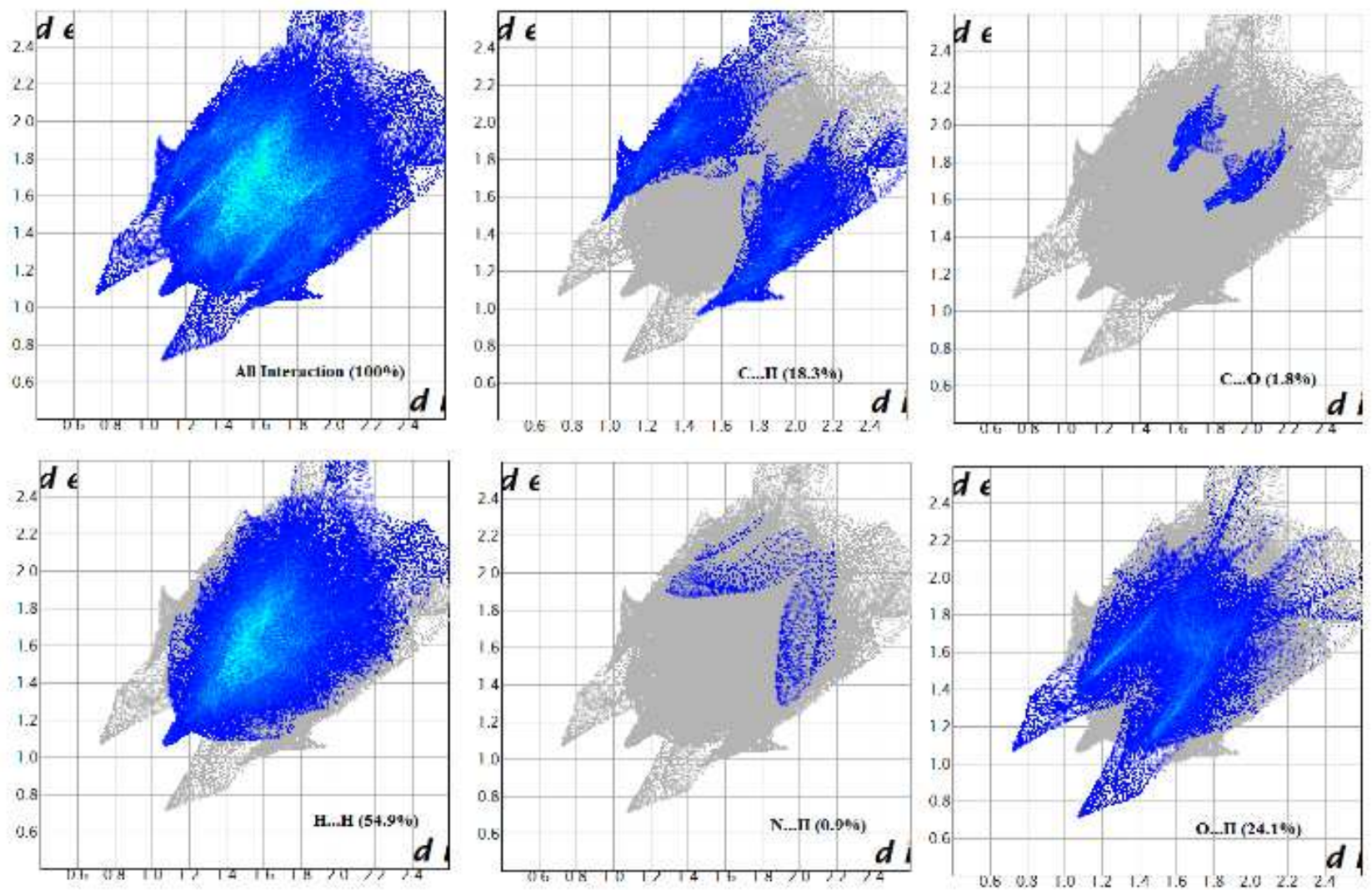

Fig. 5 Finger print plots of BBA

\subsection{Frontier Molecular Orbital (FMOs)}

Frontier molecular orbital (FMOs) plays a significant role in electrical and optical properties and are also used in the assessment of the chemical properties of the molecule[32]. The molecular orbital functions are plotted as surfaces around the molecular structure. The HOMO exhibits the ability to donate electrons and LUMO exhibits the ability to accept electrons. The HOMO and LUMO energy gap are the most important parameters for chemical reactivity and kinetic stability of the molecule. A large value of the HOMO-LUMO energy gap means high kinetic stability and low chemical reactivity. The lower HOMO-LUMO energy gap is the most significant parameter for the chemical reactivity, which explains intramolecular charge transfer (ICT) within the molecules [33] which is responsible for the bioactivity of the molecule. To 
evaluate the energy behavior of the BBA molecule, the HOMO, LUMO and HOMO-LUMO energy gaps have been calculated by B3LYP level with 6-311++G(d,p) method. HOMO and LUMO are calculated (Table 2) to be $-5.7006 \mathrm{eV}$ and $-1.2466 \mathrm{eV}$, respectively. The HOMOLUMO energy gap $4.454 \mathrm{eV}$ with the green and red counties represent the molecular orbital (MOs) with opposite phases (Fig. 6). The HOMO is located on $\mathrm{C}_{29}, \mathrm{C}_{37}, \mathrm{C}_{38}, \mathrm{C}_{39}, \mathrm{C}_{41}, \mathrm{C}_{42}, \mathrm{C}_{46}, \mathrm{H}_{68}, \mathrm{~N}_{78}$, and $\mathrm{O}_{83}$ and partially on $\mathrm{C}_{51}, \mathrm{H}_{30}, \mathrm{H}_{34}, \mathrm{H}_{36}, \mathrm{C}_{76}$, as well as $\mathrm{H}_{77}$ while the LUMO is localized on $\mathrm{C}_{54}, \mathrm{C}_{57}, \mathrm{C}_{58}, \mathrm{C}_{71}, \mathrm{C}_{74}, \mathrm{H}_{53}, \mathrm{H}_{59}$, and $\mathrm{H}_{75}$ and partially on $\mathrm{O}_{28}, \mathrm{C}_{69}, \mathrm{H}_{55}, \mathrm{H}_{84}, \mathrm{O}_{80}, \mathrm{H}_{70}$ and $\mathrm{N}_{79}$. This results in the large energy gap of $4.454 \mathrm{eV}$ for BBA molecule, which shows that it would be thermodynamically stable. In brucine the methoxy groups attached to benzene ring will increase the electron charge density. The benzilate aromatic rings also have higher electron charge density. Therefore, no charge transfer can occur between these aromatic rings. So, HOMO-LUMO gap is higher.

From the HOMO and LUMO energy, and the density functional theory (DFT) were used to realize the chemical reactivity. The electron affinity (A) and ionization potential (I) are equal to orbital energies of HOMO-LUMO as A=-ELumo and $\mathrm{I}=-$-Еномо. The electron affinity and ionization potential were found as 5.7006 and $1.2466 \mathrm{eV}$, respectively. The electronegativity $(\chi=$ $\left.\frac{I+A}{2}\right)$, chemical potential $(\mu=-\chi)$, chemical hardness $\left(\eta=\frac{\Delta E}{2}\right)$ chemical softness $(\sigma=1 / 2 \eta)$, electrophilicity index $\left(\omega=\frac{\mu^{2}}{2 n}\right)$ and nucleophilicity index $\left(\mathrm{N}=\frac{1}{\omega}\right)$ are linked to their chemical reactivity and electrostatic surface. Electrophiles are classified based on the electrophilicity index as marginal $(\omega<0.80 \mathrm{eV})$ moderate $(1.50>\omega>0.86 \mathrm{eV})$ and acid strong $(\omega>1.50 \mathrm{eV})$. The nucleophiles are classified as moderate $(3.00 \mathrm{~N}>2.00 \mathrm{eV})$, marginal $(\mathrm{N}<2.00 \mathrm{eV})$ and strong $(\mathrm{N}>3.00 \mathrm{eV})[34]$. According to the classification, the compound is a strong electrophile and 
marginal nucleophile. The strong electrophilic nature of the title compound suggests that in a biological activity it can accept electron density.
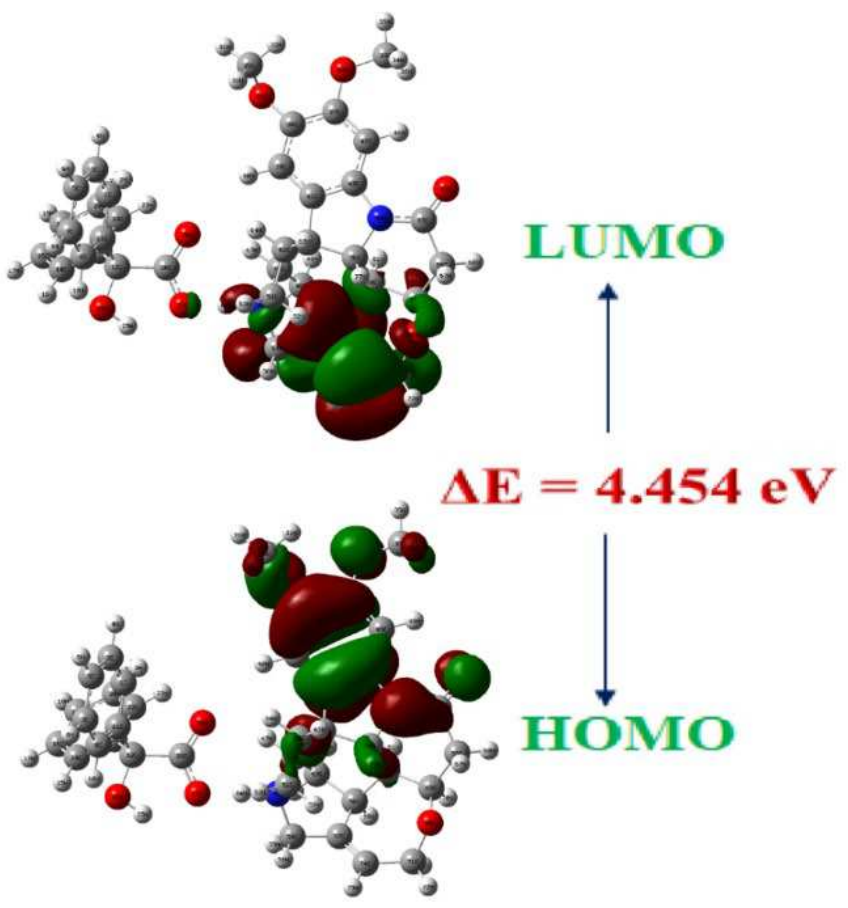

Fig. 6 Comparative HOMO and LUMO graphical representation

Table 2. Calculated Energy Values by B3LYP/6-311++G(d,p) Method

\begin{tabular}{|l|l|}
\hline Molecular Properties & B3LYP/6-311++G(d,p) \\
\hline Eнomo $(\mathrm{eV})$ & -5.7006 \\
\hline ELumo $(\mathrm{eV})$ & -1.2466 \\
\hline Energy gap (eV) & 4.454 \\
\hline Ionization potential (IP) & 5.7006 \\
\hline Electron affinity $(\mathrm{EA})$ & 1.2466 \\
\hline Electronegativity $(\chi)$ & 3.4736 \\
\hline Chemical potential $(\mu)$ & -3.4736 \\
\hline Chemical hardness $(\eta)$ & 2.227 \\
\hline Chemical softness $(\mathrm{S})$ & 0.4490 \\
\hline
\end{tabular}




\begin{tabular}{|l|l|}
\hline Electrophilicity index $(\omega)$ & 2.7089 \\
\hline Nucleophilicity index $\left(\frac{1}{\omega}\right)$ & 0.3691 \\
\hline
\end{tabular}

\subsection{Stabilization energy of natural bond order (NBO)}

The natural bond order calculation was carried on the compound to determine the electron donor-acceptor interactions in the molecule using NBO 5.1 programmer implemented in the Gaussian 09W package at the DFT/B3LYP/6-311++G(d,p) level of theory. The orbital prefers the hyper conjugative and resonance. The highest interaction energy was between the $\mathrm{N} 79-\mathrm{LP}(1) \rightarrow \mathrm{H} 84-\mathrm{LP} *(1)$ was $322.86 \mathrm{kcal} / \mathrm{mol}$; this is the interaction between the most basic nitrogen in brucine with a proton. The next highest energy interaction was between $\mathrm{O} 27-\mathrm{LP}(2) \rightarrow \mathrm{H} 84-\mathrm{LP} *(1) \quad(118.82 \mathrm{kcal} / \mathrm{mol})$. This interaction is due to $-\mathrm{COO}^{-}$and $\mathrm{H}^{+}$, which is expected to be stronger. The interaction energy of $74.80 \mathrm{kcal} / \mathrm{mol}$ was due to carboxylate anion resonance energy which is a stable one. Other minor energy interactions like $\pi \rightarrow \pi^{*}, \sigma \rightarrow \sigma^{*}, \mathrm{n} \rightarrow \pi^{*}$, and $\mathrm{n} \rightarrow \sigma^{*}$ have also been computed and their values were found to be lesser. The conjugation between $\mathrm{N}-\mathrm{C}=\mathrm{O}$ was calculated as $51.53 \mathrm{kcal} / \mathrm{mol}$. The molecule is resonance stabilized and suitable for any medical applications.

\subsection{Molecular Electrostatic Potential (MEP)}

The electric charge distribution in the molecule influences the following factors such as vibrational spectroscopy, electrostatic potential, acid-base properties, etc[35]. The molecular electrostatic potential (MEP) is an effective tool for identifying and ranking the hydrogen bond donating and accepting sites in organic compounds[36]. MEP correlate crystal packing with their relative strengths of hydrogen-bond donors and acceptors for 
understanding intermolecular interactions and other properties of crystalline materials[37]. The molecular electrostatic potential image (Fig. 7) of brucinium benzilate [BBA]. It is clear that red and yellow regions indicate the high electronegative potential on benzilate moiety due to $\mathrm{C}=\mathrm{O}$ carbonyl group. From molecular electrostatic potential, it is easy to identify electron-rich and deficient sites. The red and yellow regions on benzilate anion is an electron-rich site and most favourable for the electrophilic attack. The blue colour region in brucinium cation indicates electron-deficient site which favors nucleophilic attack. The green region in the BBA molecule indicates the neutral site. The drug-receptor and enzymesubstrate interactions of the molecule can be predicted by molecular electrostatic potential maps.

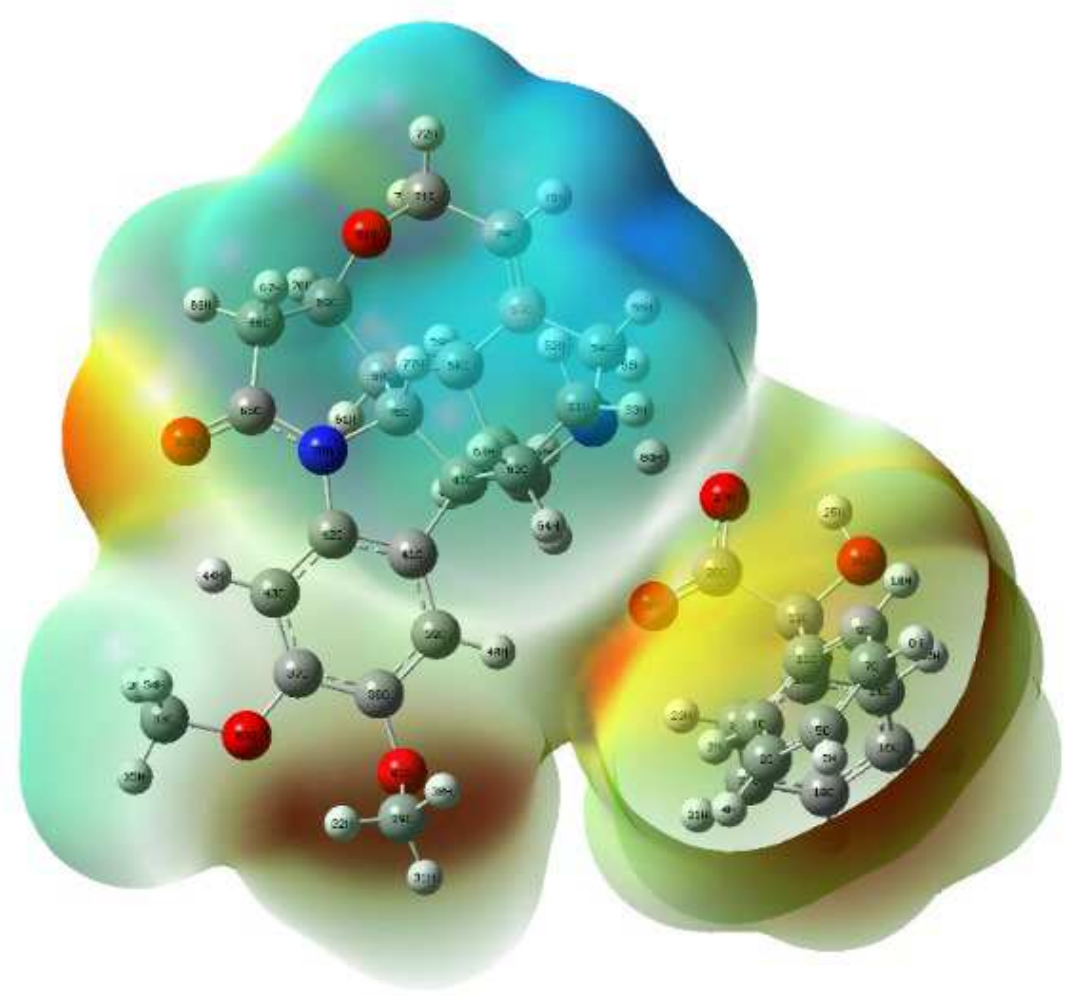

Fig. 7 Molecular electrostatic potential maps of brucinium benzilate

\section{3. ${ }^{1} \mathrm{H}$ and ${ }^{13} \mathrm{C}$ NMR spectroscopy}


$\delta$ in ppm; 7.77 - 7.52: (Aromatic H); $7.322-7.24$ (Aromatic $\mathrm{H})[38] ;$ 7.00: (Tertiary amine $\mathrm{NH}^{+}$)

(Fig. 8).

$\delta$ in ppm; 178.41: (COO-)[39, 40](Fig. 9).

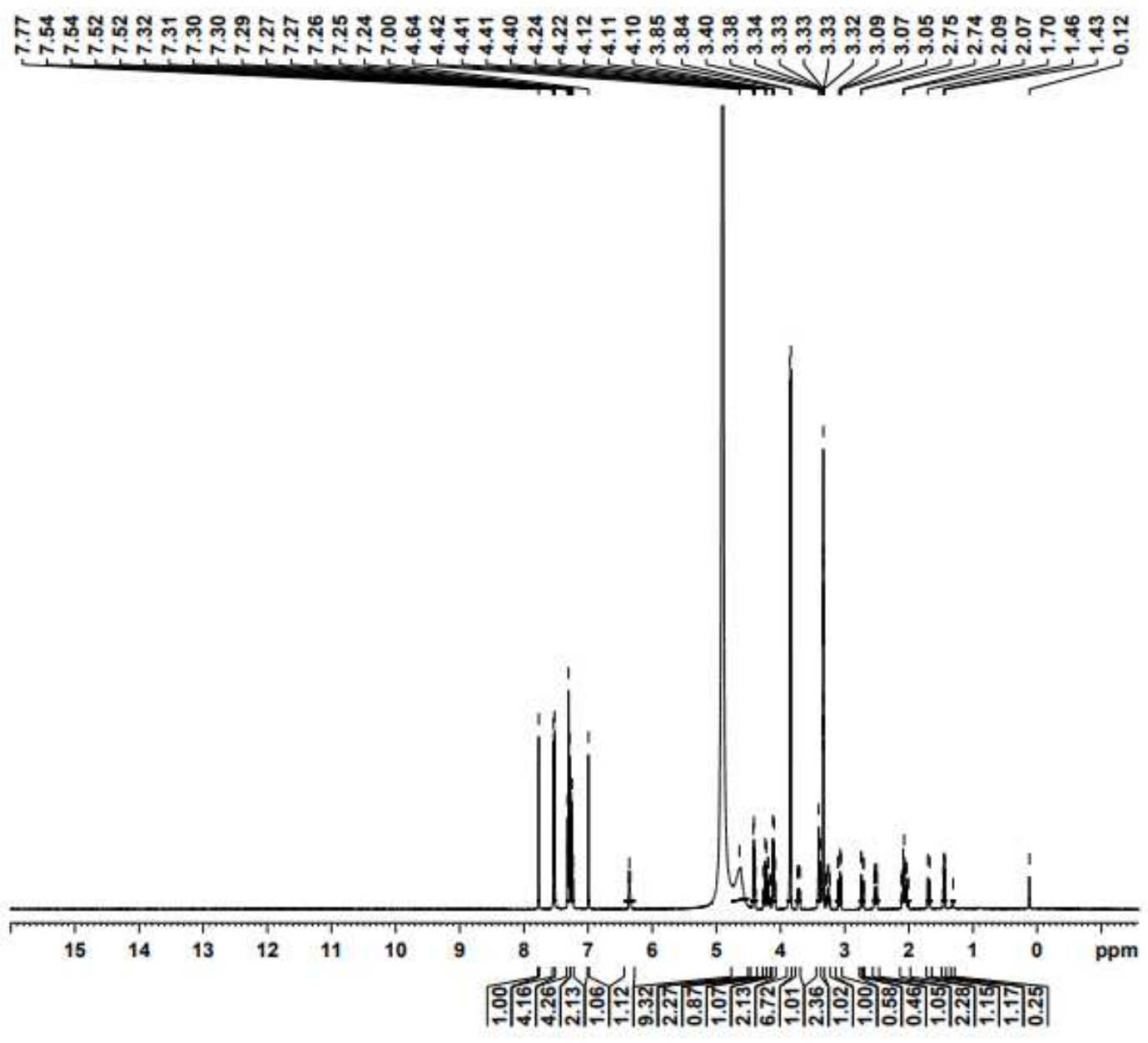

Fig. $8{ }^{1} \mathrm{H}$ NMR spectrum of BBA in MeOD 


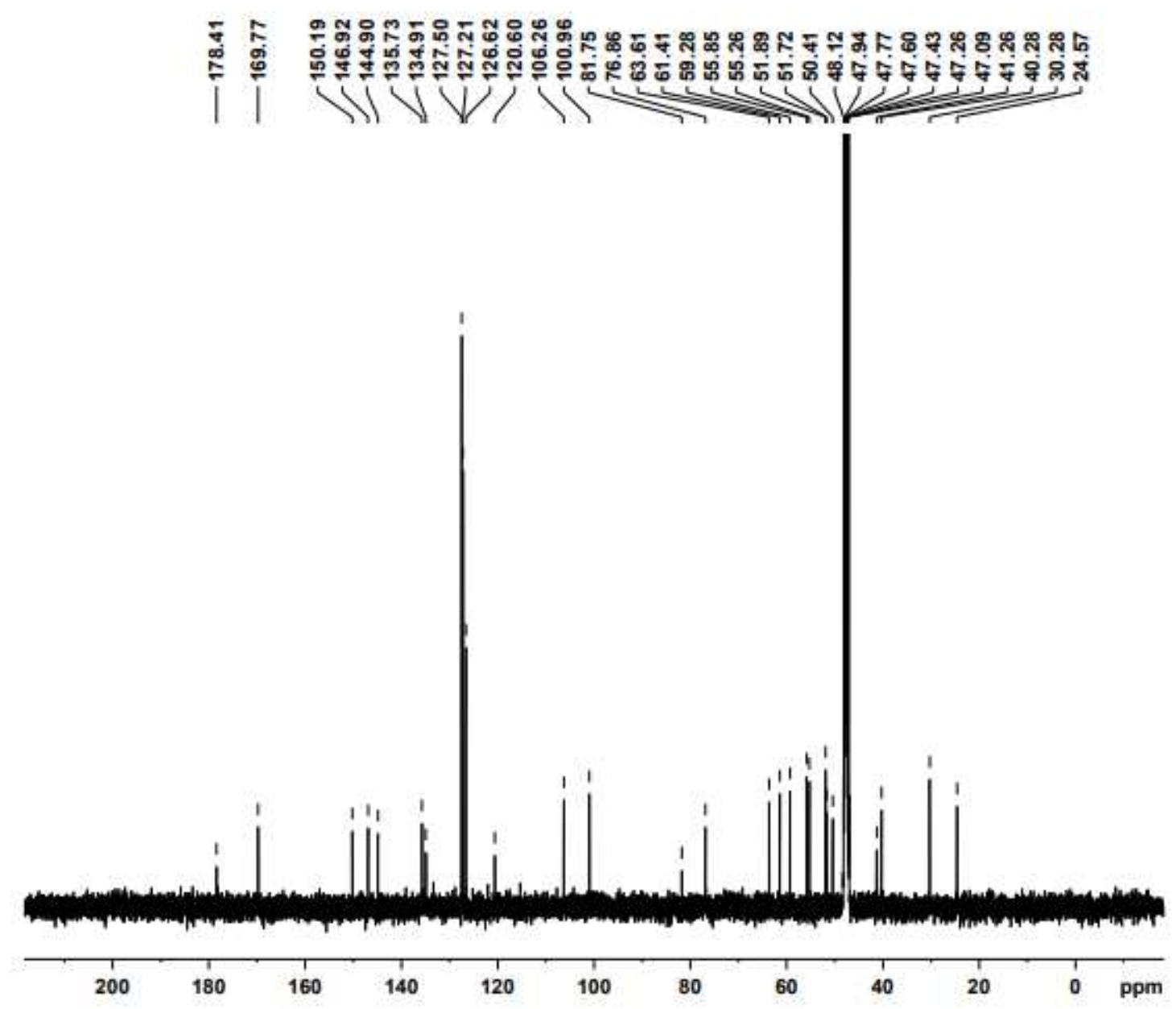

Fig. $9{ }^{13} \mathrm{C}$ NMR spectrum of BBA in MeOD

\subsection{Vibrational frequencies analysis}

The IR and Raman spectra of BBA are presented in Fig. 10 and 11, respectively. One peaks at $3285 \mathrm{~cm}^{-1}(\mathrm{vw}): v(\mathrm{O}-\mathrm{H})+v(\mathrm{~N}-\mathrm{H}) ; 3170 \mathrm{~cm}^{-1}, 3070 \mathrm{~cm}^{-1}(\mathrm{vw}): v(\mathrm{C}-\mathrm{H})$ Aromatic; $2924 \mathrm{~cm}^{-1}(\mathrm{w})$, $3006 \mathrm{~cm}^{-1}(\mathrm{vw}): v(\mathrm{C}-\mathrm{H})$ Aliphatic; $1665.9 \mathrm{~cm}^{-1}(\mathrm{vs}): v\left(\mathrm{COO}^{-}\right)_{\text {asym }} ; 1496.5 \mathrm{~cm}^{-1}: v(\mathrm{C}=\mathrm{N}) ; 1500$ $\mathrm{cm}^{-1}$ (sh): $v(\mathrm{C}=\mathrm{O}) ; 1191.9 \mathrm{~cm}^{-1}$ (vs), $1164.31 \mathrm{~cm}^{-1}$ (s), $1110.44 \mathrm{~cm}^{-1}$ (vs): $v(\mathrm{C}-\mathrm{O})$ have been observed in ATR-IR spectrum. The protonated NH frequency has been not observed in Raman due to high polarity. The peaks at $3063 \mathrm{~cm}^{-1}(\mathrm{~s}), 3011 \mathrm{~cm}^{-1}(\mathrm{~m}): v(\mathrm{C}-\mathrm{H})$ Armoatic; $2964 \mathrm{~cm}^{-1}(\mathrm{~s}), 2917$ 
$\mathrm{cm}^{-1}(\mathrm{~s}), 2881 \mathrm{~cm}^{-1}(\mathrm{~m}): v(\mathrm{C}-\mathrm{H})$ Aliphatic; $1662 \mathrm{~cm}^{-1}(\mathrm{~m}): v\left(\mathrm{COO}^{-}\right)_{\text {asym }}$ $1607 \mathrm{~cm}^{-1}(\mathrm{~s}): v$ sym $\left(\mathrm{COO}^{-}\right)_{\mathrm{sym}}[41][42]$ have been noticed.

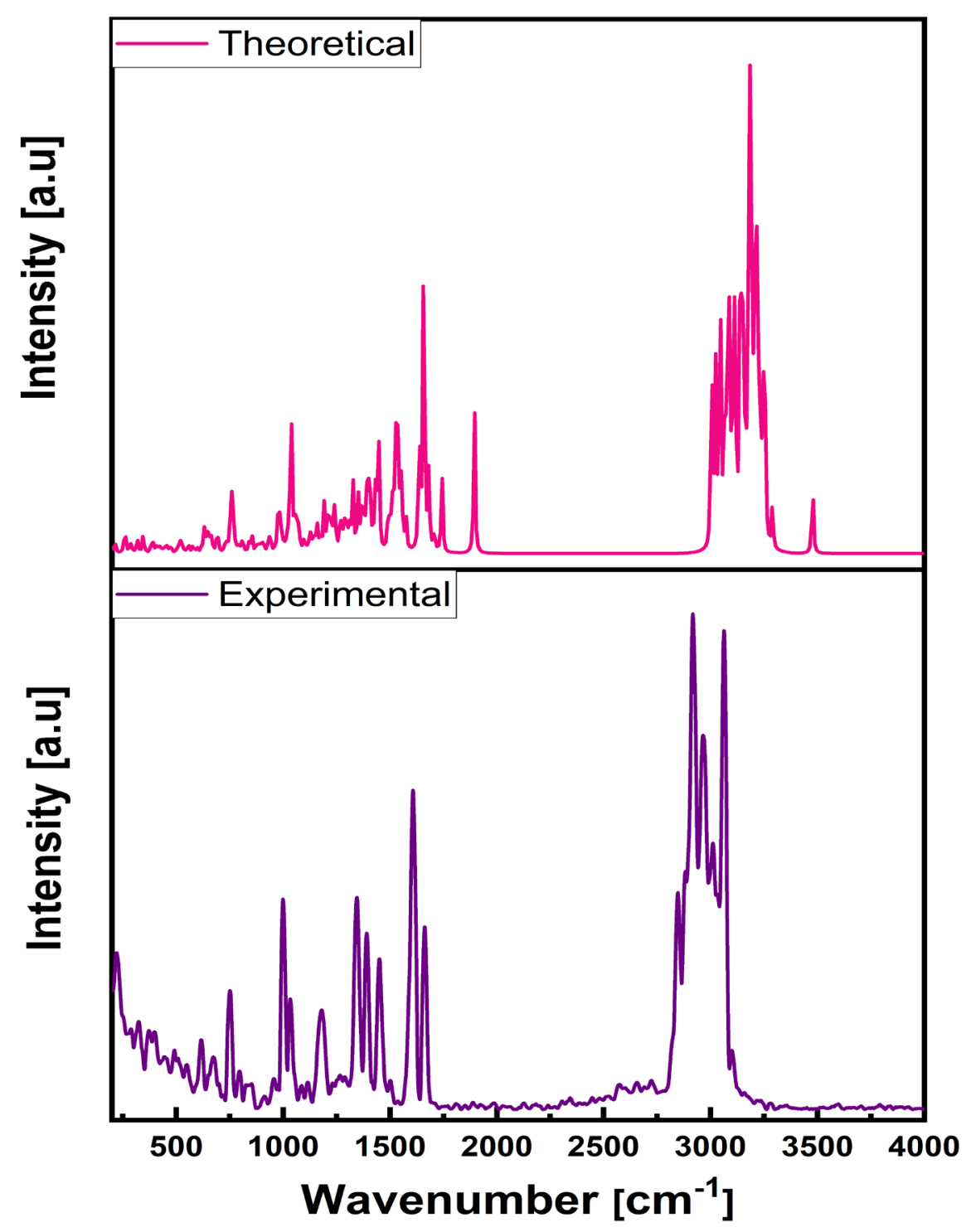

Fig. 10 Experimental and theoretical ATR-IR spectrum 


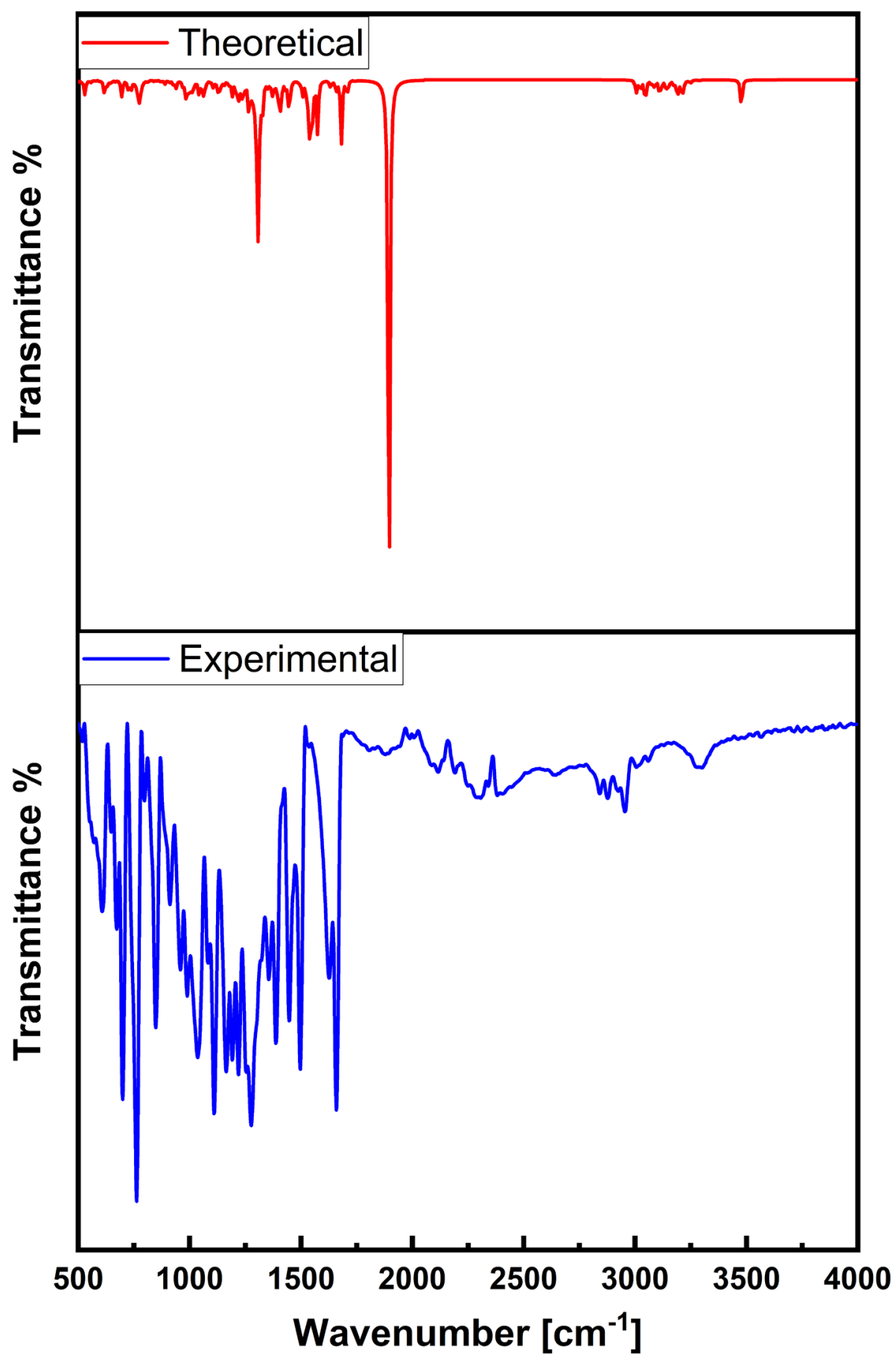

Fig. 11 Experimental and theoretical Raman spectrum 


\subsection{Biocidal activity}

The antibacterial activities of synthetic compounds were evaluated by the disc diffusion method. It was identified by studying different concentrations of both Bacillus cereus and Salmonella typhimurium bacteria in the present study $(20 \mu 1)$. The plates were incubated at $370^{\circ} \mathrm{C}$ for $24 \mathrm{~h}$. The antibacterial strains measured (Table 3) and antibacterial activity photograph is shown in Fig.12. It was found that the bacterial strain Salmonella typhimurium exhibits the highest inhibition zone in all the three concentrations $(24 \mathrm{~mm}, 15$ $\mathrm{mm}$, and $11 \mathrm{~mm}$ ) where the activity increases with increase in concentration. Results reveal that for bacterial strains, activity increases with an increase in compound concentration and the inhibition of the strains also increases. Bacillus cereus and Salmonella typhimurium used in this study.
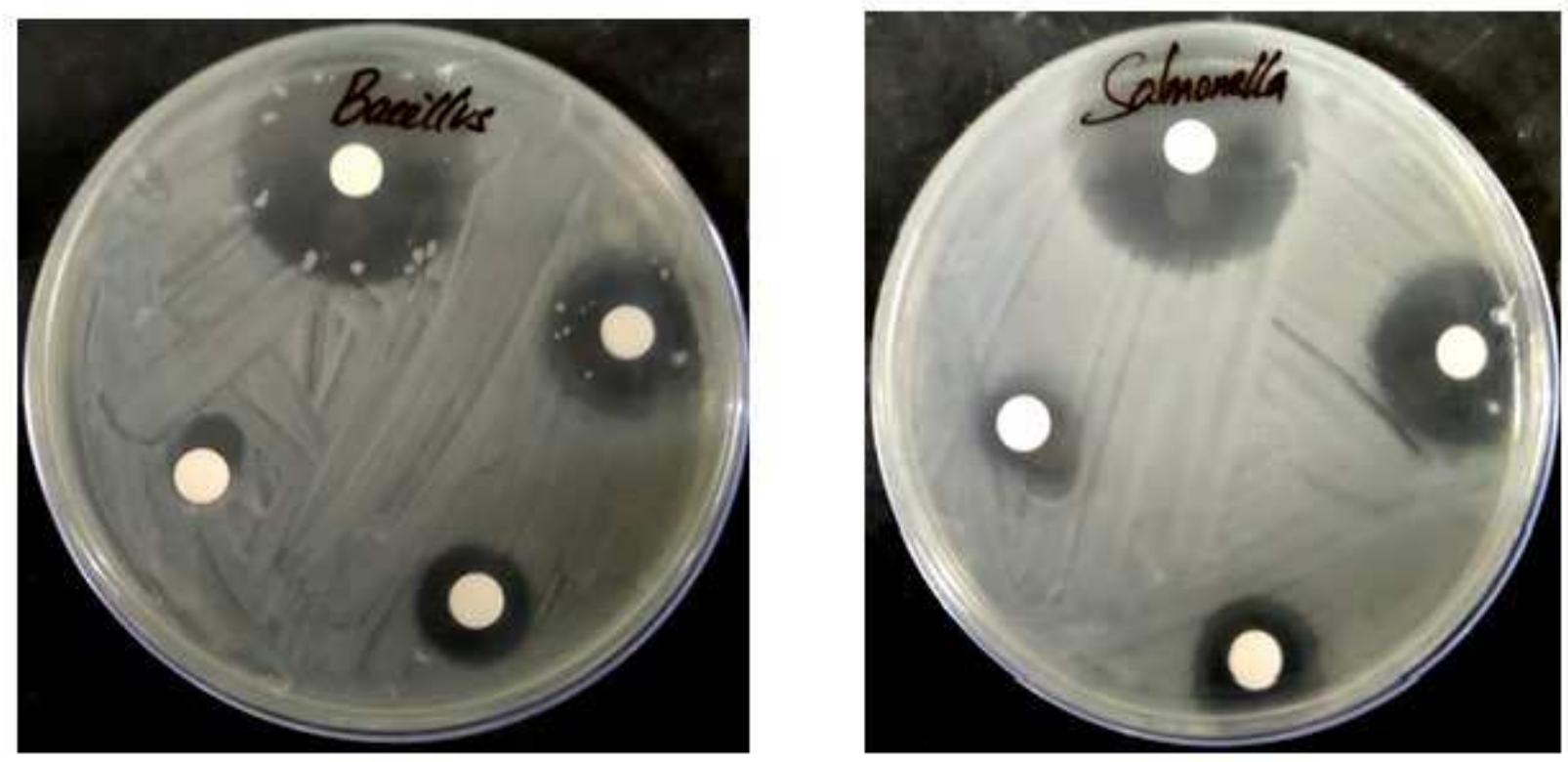

Fig. 12 Photograph of Antibacterial activities 


\section{Table 3. Antibacterial activity of BBA}

\begin{tabular}{|l|l|l|l|}
\hline \multirow{4}{*}{ Organisms } & \multicolumn{2}{l}{ Zone of Inhibition } \\
& \multicolumn{3}{|l|}{ (mm) } \\
\cline { 2 - 4 } & {$[\mathbf{B B A}](\boldsymbol{\mu g} / \mathbf{m l})$} \\
\cline { 2 - 4 } & $\mathbf{1 0 0 0}$ & $\mathbf{7 5 0}$ & $\mathbf{5 0 0}$ \\
\hline Salmonella & 24 & 15 & 11 \\
\hline Bacillus & 20 & 14 & 11 \\
\hline
\end{tabular}

\subsection{ADMET Properties}

ADMET (Absorption, Distribution, Metabolism, Excretion and Toxicity) profile of title compound and the standard drug reference of Regorafenib were evaluated using PreADMET[43] webserver. Caco-2 permeability and blood-brain barrier crossing ability of BBA were higher than the Regorafenib. Human intestinal absorption (HIA) property of the title compound was examined using drug filter rules which confirmed that the proposed drug had little higher HIA property than standard drug. The efficiency depends on the quantity of plasma protein binding (PPB) ability. The compound had higher efficiency than that of Regorafenib. The compound obeys Lipinski's five rules. The in-silico synthesized compound possesses good drug-likeness as well as ADMET properties[44], (Table 4). 
Table 4. Shows the relative ADMET profiles of the synthesized compounds (as obtained from PreADMET server).

\begin{tabular}{|l|l|l|}
\hline ADMET Properties & Tittle compound & Regorafenib \\
\hline BBB & 0.106129 & 1.31554 \\
\hline Caco2 & 39.9977 & 22.4366 \\
\hline HIA & 93.989502 & 93.518216 \\
\hline MDCK & 2.14771 & 0.0796041 \\
\hline PPB & 46.881664 & -2.49797 \\
\hline PWS & 5.94539 & 0.205199 \\
\hline BS & 34.4969 & 2.68205 \\
\hline SP & -3.92507 & 91.051013 \\
\hline CYP_2C19_inhibition & Non & Non \\
\hline CYP_2C9_inhibition & Inhibitor & Inhibitor \\
\hline CYP_2D6_inhibition & Non & Non \\
\hline CYP_2D6_substrate & Weakly & Non \\
\hline CYP_3A4_inhibition & Non & Non \\
\hline CYP-3A4 substrate & Substrate & Weakly \\
\hline Carcinogenicity in Rat & Negative & Negative \\
\hline Carcinogenicity in Mouse & Positive & Positive \\
\hline Lipinski’s rule & Suitable & Suitable \\
\hline
\end{tabular}




\section{Conclusion}

The Hirshfeld surface analysis and its associated 2D fingerprint plots have been used for a detailed exploration of molecular interactions. The frequencies of BBA from ATR-IR and FT-Raman were compared with the theoretical approaches (DFT / B3LYP method and 6$311++\mathrm{G}(\mathrm{d}, \mathrm{p})$. Analysis of FMOs suggested that the hydroxyl, carboxylate, indoline ring and benzene ring might play an essential role in its biological activity. The higher value of stabilization energy computed by the HOMO-LUMO energy gap $(\Delta \mathrm{E})$ of $4.454 \mathrm{eV}$ indicated the bioactivity of the title compound. The compound had lowest electron affinity of $1.2466 \mathrm{eV}$ and higher ionization potential of $5.7006 \mathrm{eV}$. The highest interaction is between N79-LP(1) $\rightarrow$ H84-LP*(1) and the molecule is resonance stabilized as indicated by energy calculations. The MEP surface study expressions show that the benzilate moiety ( $\mathrm{C}=\mathrm{O}$ carbonyl group) has a deep dark blue region which is considered for the nucleophilic attack. The compound obeyed all the considerations of Lipinski's five rule which showed good ADMET characteristics, which making the compound as a potential drug.

\section{Supplementary Information}

The online version contains supplementary material available at

Acknowledgements We gratefully acknowledge the support from Er.A.C.S.Arunkumar, President of Dr. M.G.R. Educational and Research Institute, Chennai, India for their support and encouragement.

Author contribution Conceptualization: $\mathrm{KC}$ and MA; methodology: $\mathrm{KC}$ and MS; formal analysis and investigation: $\mathrm{KC}$ and $\mathrm{RV}$; writing — original draft preparation: $\mathrm{KC}$ and $\mathrm{KSN}$; writing — review and editing $\mathrm{KC}, \mathrm{MA}$ and $\mathrm{KSN}$ : supervision: $\mathrm{KSN}$ and $\mathrm{MS}$ 
Financial interests: The authors declare they have no financial interests.

\section{Data availability}

CCDC: 1966353 contains the supplementary crystallographic data for this paper. This data can be obtained free of charge via https:/www.ccdc.cam.ac.uk/structures/,or by contacting the Cambridge Crystallographic Data Centre, 12 Union Road, Cambridge CB2 1EZ, UK; Tel: +44

(0)1223 336408 .

Code availability Not applicable

\section{Reference}

1. Jeseentharani V, Selvakumar J, Dayalan A, et al (2010) Preparation, characterization and crystal structure of some imino Schiff bases. J Mol Struct 966:122-128. https://doi.org/10.1016/j.molstruc.2009.12.024

2. Hisaki I, Shizuki N, Aburaya K, et al (2009) Structures of Brucinium Cholate : Bile Acid and Strychnine \& DESIGN 2009. Cryst Growth Des 1-4

3. Srivastava K, Shukla A, Karthick T, et al (2019) Molecular structure, spectroscopic signature and reactivity analyses of paracetamol hydrochloride monohydrate salt using density functional theory calculations. CrystEngComm 21:857-865. https://doi.org/10.1039/c8ce01761a

4. Verma P, Srivastava A, Shukla A, et al (2019) Vibrational spectra, hydrogen bonding interactions and chemical reactivity analysis of nicotinamide-citric acid cocrystals by an experimental and theoretical approach. New J Chem 43:15956-15967. https://doi.org/10.1039/c9nj03085a

5. Shukla A, Khan E, Alsirawan MHDB, et al (2019) Spectroscopic (FT-IR, FT-Raman, and 
13C SS-NMR) and quantum chemical investigations to provide structural insights into nitrofurantoin-4-hydroxybenzoic acid cocrystals. New J Chem 43:7136-7149. https://doi.org/10.1039/c8nj05946b

6. Agrawal SS, Saraswati S, Mathur R, Pandey M (2011) Cytotoxic and antitumor effects of brucine on Ehrlich ascites tumor and human cancer cell line. Life Sci 89:147-158. https://doi.org/10.1016/j.lfs.2011.05.020

7. Lu L, Huang R, Wu Y, et al (2020) Brucine: A Review of Phytochemistry, Pharmacology, and Toxicology. Front Pharmacol 11:1-6. https://doi.org/10.3389/fphar.2020.00377

8. Serasanambati M, Chilakapati SR, Manikonda PK, et al (2015) Anticancer effects of brucine and gemcitabine combination in MCF-7 human breast cancer cells. Nat Prod Res 29:484-490. https://doi.org/10.1080/14786419.2014.951932

9. Saraswati S, Agrawal SS (2013) Brucine, an indole alkaloid from Strychnos nux-vomica attenuates VEGF-induced angiogenesis via inhibiting VEGFR2 signaling pathway in vitro and in vivo. Cancer Lett 332:83-93. https://doi.org/10.1016/j.canlet.2013.01.012

10. Smith G, Wermuth UD, Young DJ (2010) Hydrate stabilization in the three-dimensional hydrogen-bonded structure of the brucinium compound, bis(2,3-dimethoxy-10oxostrychnidinium) biphenyl-4,4'-disulfonate hexahydrate. J Chem Crystallogr 40:520525. https://doi.org/10.1007/s10870-010-9689-7

11. Białońska A, Ciunik Z (2006) Brucinium 3,5-dinitrobenzoate methanol solvate, methanol disolvate and trihydrate. Acta Crystallogr Sect C Cryst Struct Commun 62:450-453. https://doi.org/10.1107/S0108270106021068 
12. Road WM, Building MS (1998) Brucinium Hydrogen Fumarate Sesquihydrate and Brucinium Hydrogen Maleate. 1948-1951. https://doi.org/10.1107/S0108270198010324

13. Bialońska A, Ciunik Z (2004) Brucine and two solvates. Acta Crystallogr Sect C Cryst Struct Commun 60:853-855. https://doi.org/10.1107/S0108270104024874

14. Smith G, Wermuth UD, White JM (2005) Hydrogen bonding in brucinium dihydrogen citrate trihydrate at $130 \mathrm{~K}$. Acta Crystallogr Sect C Cryst Struct Commun 61:621-624. https://doi.org/10.1107/S0108270105028222

15. Białońska A, Ciunik Z (2006) Strychninium N-phthaloyl- $\beta$-alaninate N-phthaloyl- $\beta$ alanine and brucinium N-phthaloyl- $\beta$-alaninate 5.67-hydrate. Acta Crystallogr Sect C Cryst Struct Commun 62:182-185. https://doi.org/10.1107/S0108270106005555

16. Smith G, Wermuth UD, White JM (2007) Pseudopolymorphism in brucine: Brucine-water (1/2), the third crystal hydrate of brucine. Acta Crystallogr Sect C Cryst Struct Commun 63:489-492. https://doi.org/10.1107/S0108270107032295

17. Białońska A, Ciunik Z (2007) Isomorphous brucinium 4-nitro-benzoate methanol solvate and brucinium 4-nitro-benzoate dihydrate. Acta Crystallogr Sect C Cryst Struct Commun 63:120-122. https://doi.org/10.1107/S010827010605517X

18. Sudha R, Brindha Devi P, Kanakam CC, Nithya G (2017) Docking studies for various antibacterial benzilate derivatives. Asian J Pharm Clin Res 10:268-271. https://doi.org/10.22159/ajpcr.2017.v10i4.16713

19. Vyas M, Sakore TD, Biswas AB (1978) The Structure of Potassium Benzilate. Acta Cystallographica Sect B B34:1345-1347. 
https://doi.org/https://doi.org/10.1107/S0567740878005531

20. Sheldrick GM (2015) SHELXT - Integrated space-group and crystal-structure determination. Acta Crystallogr Sect A Found Crystallogr 71:3-8. https://doi.org/10.1107/S2053273314026370

21. Sheldrick GM (2015) Crystal structure refinement with SHELXL. Acta Crystallogr Sect C Struct Chem 71:3-8. https://doi.org/10.1107/S2053229614024218

22. Bruker (2004) APEX2, SAINT, XPREP and SADABS. Bruker AXS Inc., Madison, Wisconsin, USA

23. et al. Frisch, M. J.; Trucks, G. W.; Schlegel, H. B.; Scuseria, G. E.; Robb, M. A.; Cheeseman, J. R.; Scalmani, G.; Barone, V.; Mennucci, B.; Petersson GA. (2010) Gaussian 09

24. Clary D, Sundström V, Zewail A (2005) Chemical Physics Letters: Editorial. Chem Phys Lett 404:1. https://doi.org/10.1016/j.cplett.2005.01.034

25. Lee, C.; Yang, W.; Parr P. (1988) Development of the Colle-Salvetti correlation-energy formula into a functional of the electron density. Phys Rev B 37:

26. Glenening, E.D.;. Reed, A.E.; Carpenter, J.E.; Weinhold, F.; Bohmann, J.A.; Morales CM (2001) NBO version 5.0

27. Weinhold F (2001) Chemistry: A new twist on molecular shape. Nature 422:539-541

28. Erbudak, M.; Gubanov, V.A.; Kurmaev EZ (1978) The electronic structure of NBO: Theory and experiment. Solid State Commun 27:

29. Reed, A.E.; Curtis, L.A.; Weinhold F (1988) Intermolecular interactions from a natural 
bond orbital, donor-acceptor viewpoint. Chem Rev 88:899-926

30. McKinnon JJ, Jayatilaka D, Spackman MA (2007) Towards quantitative analysis of intermolecular interactions with Hirshfeld surfaces. Chem Commun 3814-3816. https://doi.org/10.1039/b704980c

31. Turner, M. J., McKinnon, J. J., Wolff, S. K., Grimwood, D. J., Spackman, P. R., Jayatilaka, D. \& Spackman MA (2017) Crystal Explorer17

32. Foresman J, Frisch A (2015) Exploring Chemistry with Electronic Structure Methods

33. Khayer K, Haque T (2020) Density functional theory calculation on the structural, electronic, and optical properties of fluorene-based azo compounds. ACS Omega 5:45074531. https://doi.org/10.1021/acsomega.9b03839

34. Yılmaz ZT, Odabaşoğlu HY, Şenel P, et al (2020) A novel 3-((5-methylpyridin-2yl)amino)isobenzofuran-1(3H)-one: Molecular structure describe, $\mathrm{X}$-ray diffractions and DFT calculations, antioxidant activity, DNA binding and molecular docking studies. J Mol Struct 1205:127585. https://doi.org/10.1016/j.molstruc.2019.127585

35. Cai YY, Xu LY, Chai LQ, Li YX (2020) Synthesis, crystal structure, TD/DFT calculations and Hirshfeld surface analysis of 1-(4-((Benzo)dioxol-5ylmethyleneamino)phenyl)ethanone oxime. J Mol Struct 1204:127552. https://doi.org/10.1016/j.molstruc.2019.127552

36. Dey T, Praveena KSS, Pal S, Mukherjee AK (2017) Three oxime ether derivatives: Synthesis, crystallographic study, electronic structure and molecular electrostatic potential calculation. J Mol Struct 1137:615-625. https://doi.org/10.1016/j.molstruc.2017.02.089 
37. Dey T, Chatterjee P, Bhattacharya A, et al (2016) Three Nimesulide Derivatives: Synthesis, Ab Initio Structure Determination from Powder X-ray Diffraction, and Quantitative Analysis of Molecular Surface Electrostatic Potential. Cryst Growth Des 16:1442-1452. https://doi.org/10.1021/acs.cgd.5b01547

38. AlRabiah H, Abdel-Aziz HA, Mostafa GAE (2019) Charge transfer complexes of brucine with chloranilic acid, 2,3-dichloro-5,6-dicyano-1,4-benzoquinone and tetracyanoquinodimethane: Synthesis, spectroscopic characterization and antimicrobial activity. J Mol Liq 286:110754. https://doi.org/10.1016/j.molliq.2019.04.031

39. Hill DK, Jamin Y, Orton MR, et al (2013) 1H NMR and hyperpolarized 13C NMR assays of pyruvate-lactate: A comparative study. NMR Biomed 26:1321-1325. https://doi.org/10.1002/nbm.2957

40. Ibert M, Fuerts P, Merbouh N, et al (2011) Evidence of benzilic rearrangement during the electrochemical oxidation of D-glucose to D-glucaric acid. Carbohydr Res 346:512-518. https://doi.org/10.1016/j.carres.2010.12.017

41. Socrates G (2001) Infrared and Raman characteristic group frequencies. Tables and charts

42. SHRINER RL, HERMANN CKF, MORRILL TC, et al (2004) Th e Syste mati c Identification of Organic Compounds 8th Edition

43. Azad I, Akhter Y, Khan T, et al (2020) Synthesis, quantum chemical study, AIM simulation, in silico ADMET profile analysis, molecular docking and antioxidant activity assessment of aminofuran derivatives. J Mol Struct 1203:127285.

https://doi.org/https://doi.org/10.1016/j.molstruc.2019.127285 
44. Murugavel S, Ravikumar C, Jaabil G, Alagusundaram P (2019) Synthesis, computational quantum chemical study, in silico ADMET and molecular docking analysis, in vitro biological evaluation of a novel sulfur heterocyclic thiophene derivative containing 1,2,3triazole and pyridine moieties as a potential human topois. Comput Biol Chem 79:73-82. https://doi.org/https://doi.org/10.1016/j.compbiolchem.2019.01.013 
Figures

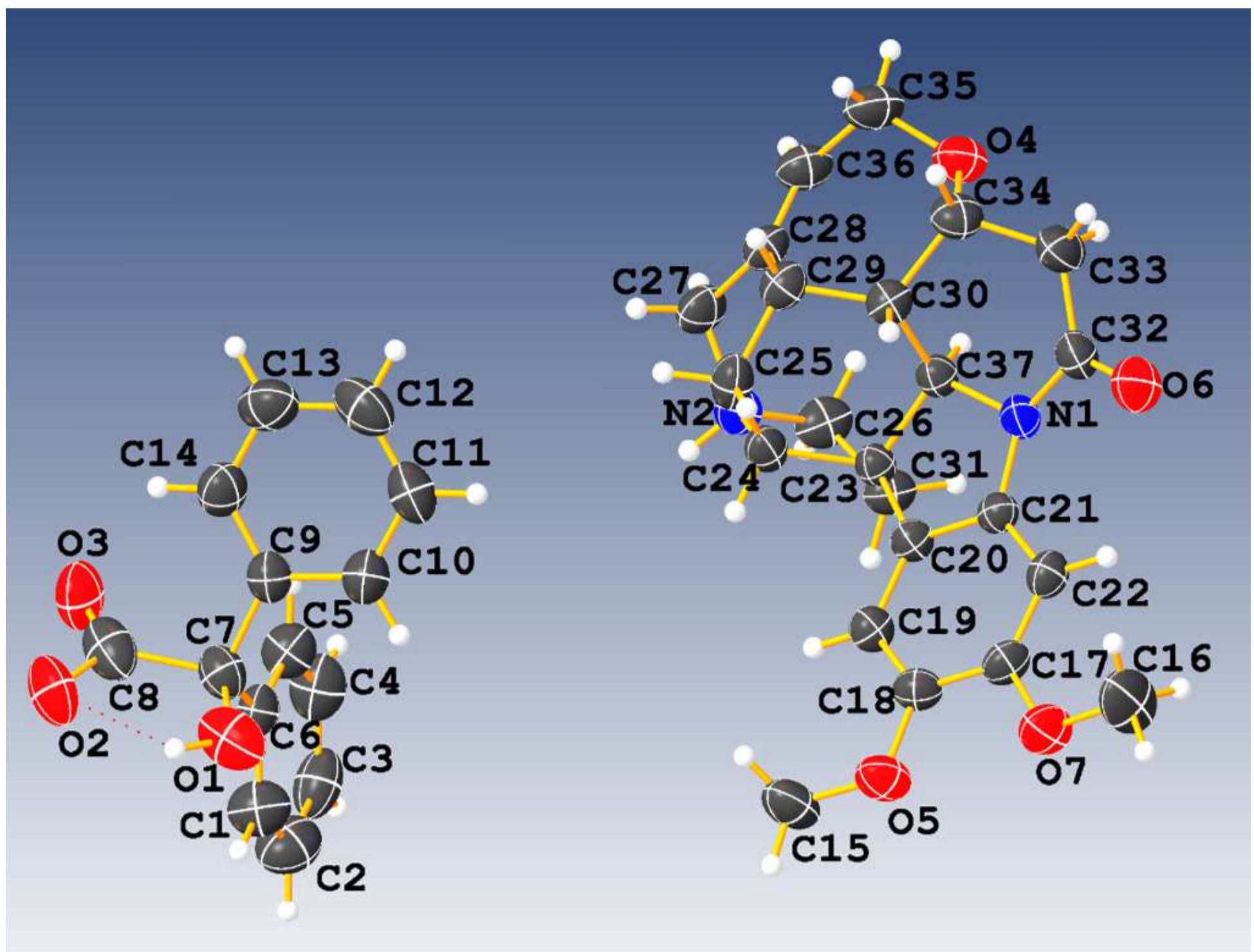

Figure 1

Ortep view of BBA 


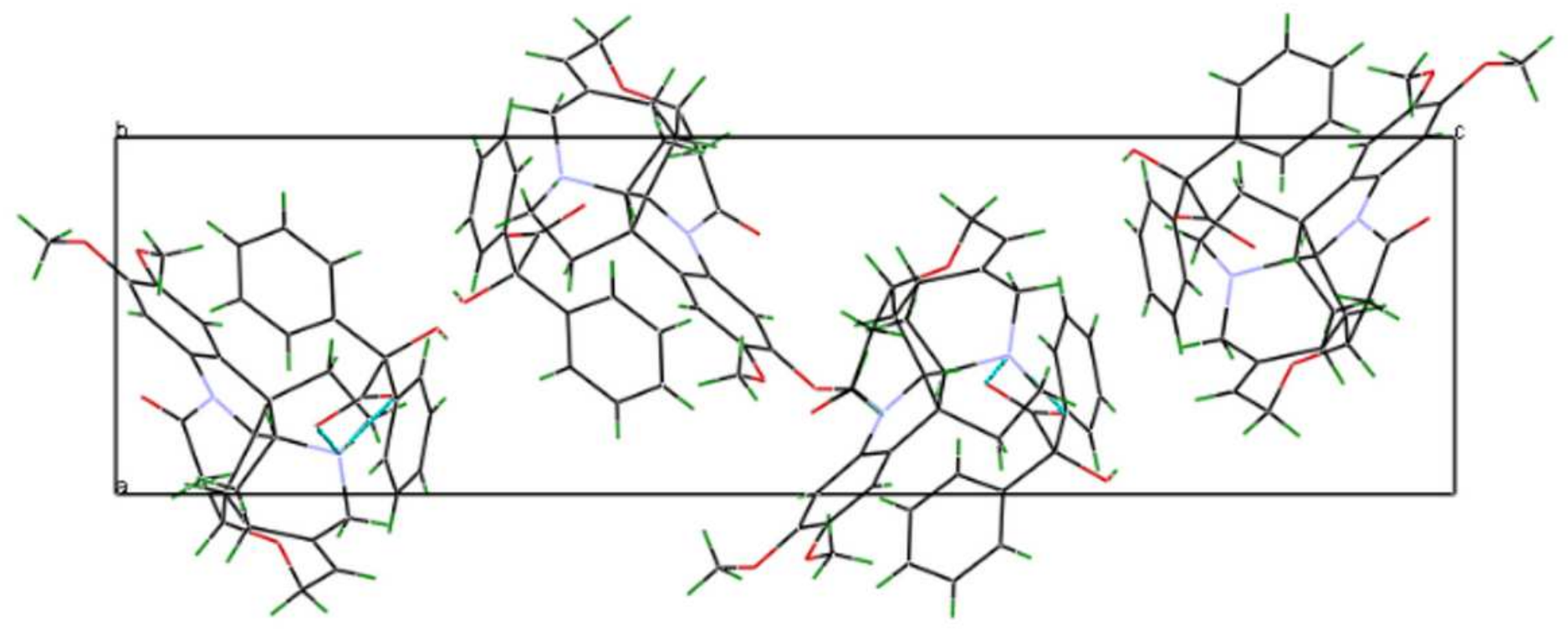

Figure 2

Molecular packing of BBA 

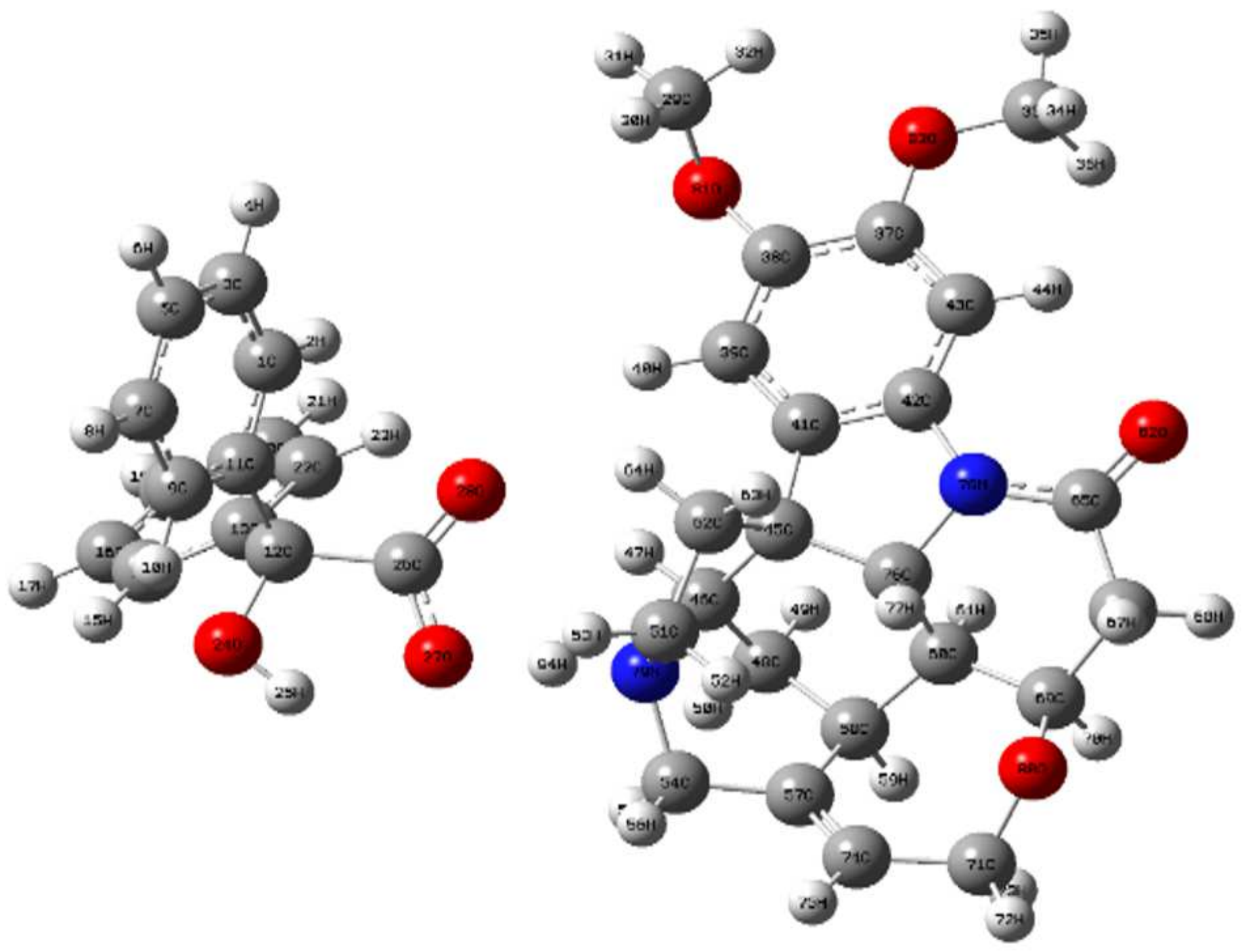

Figure 3

Optimized geometry of BBA 


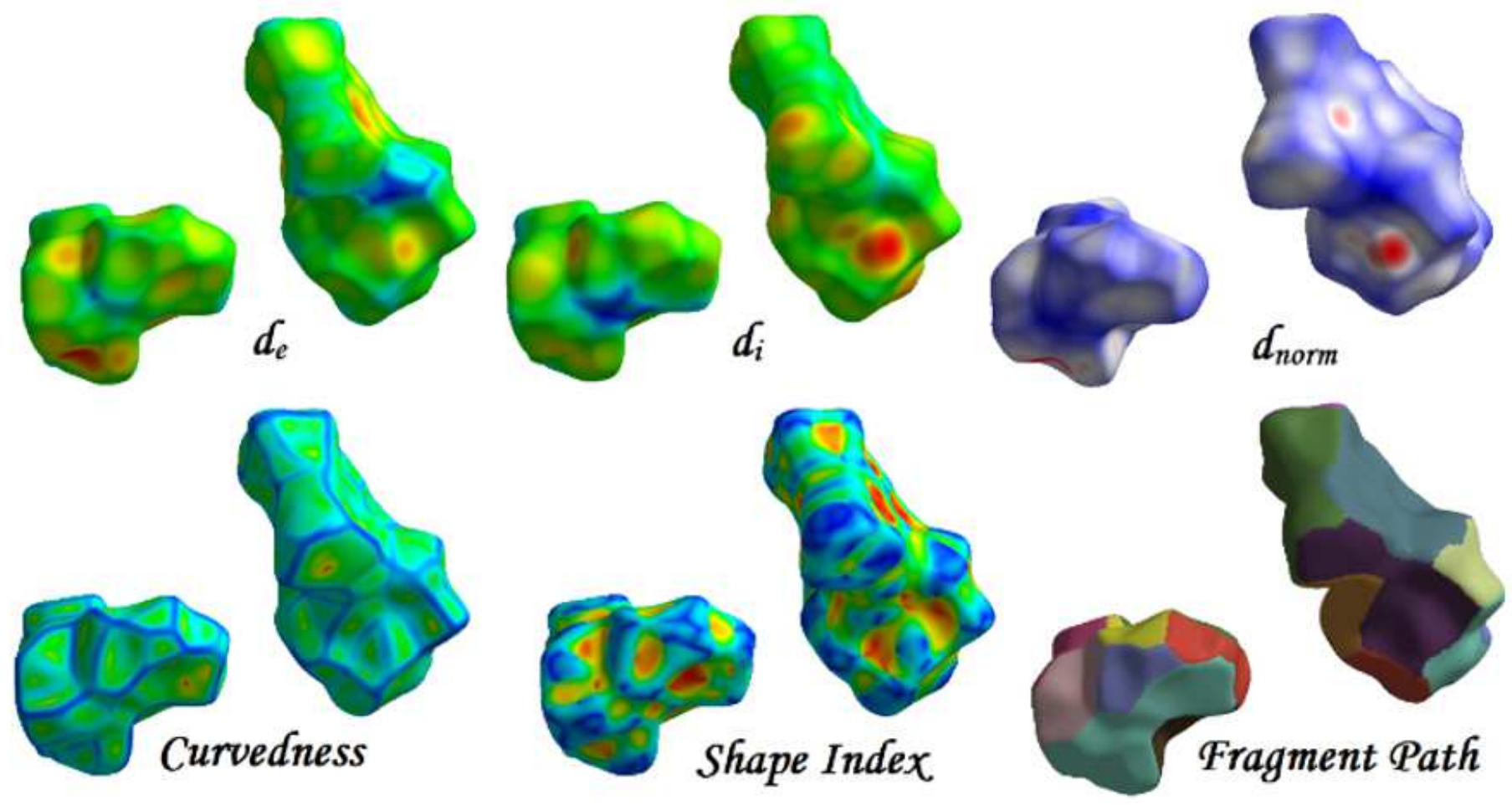

Figure 4

Hirshfeld surface analysis of brucinium benzilate 

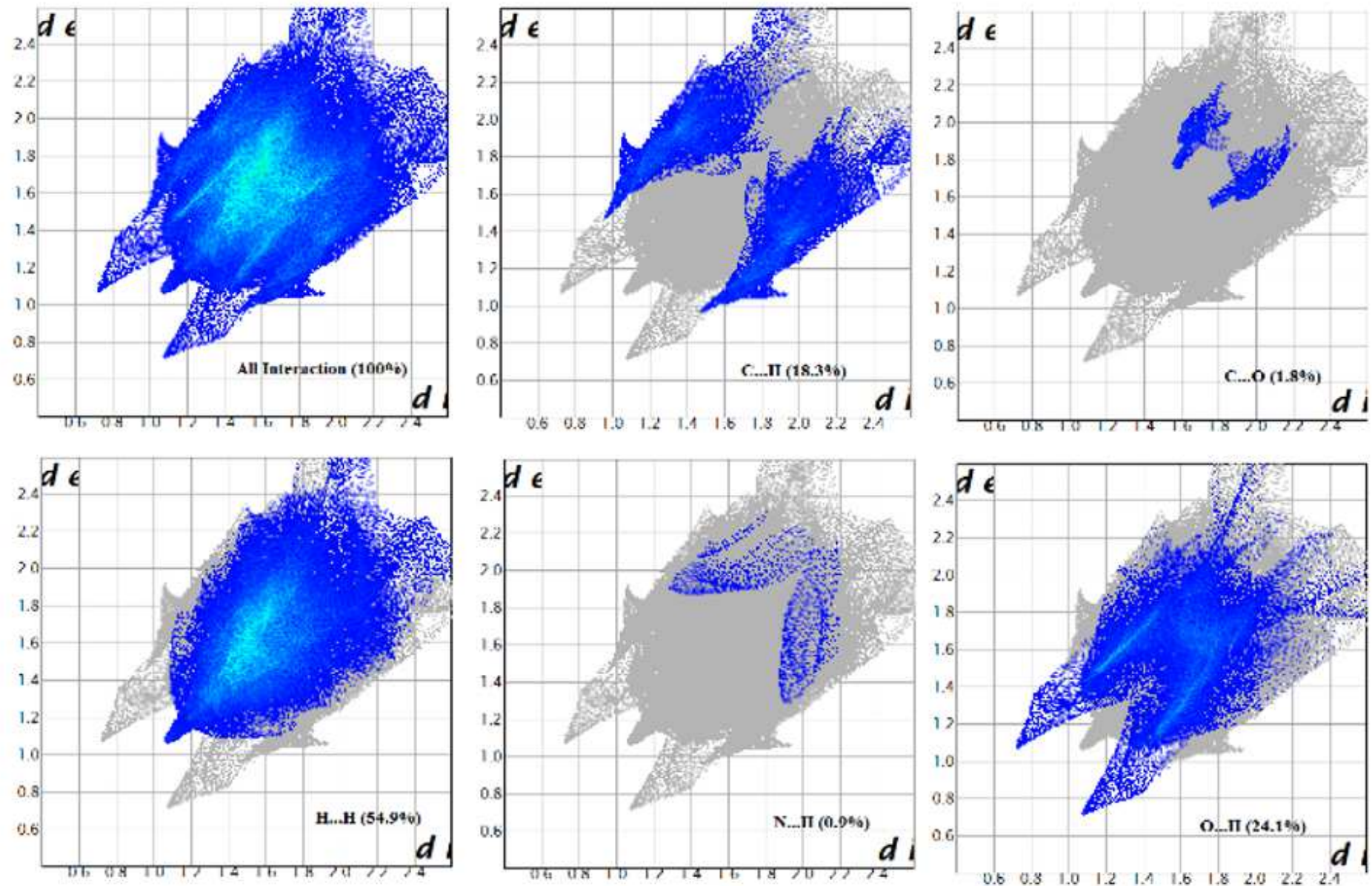

Figure 5

Finger print plots of BBA 

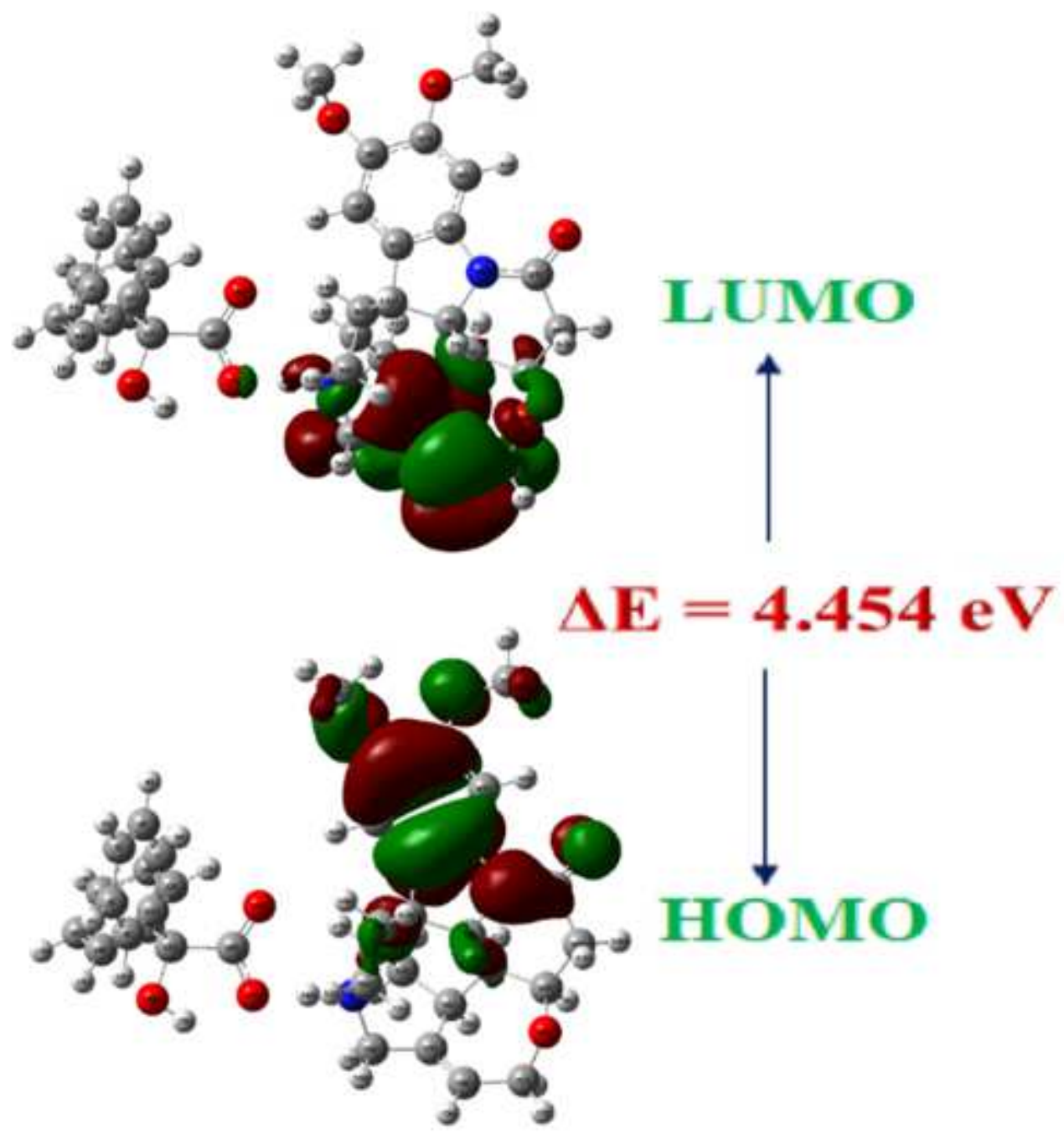

Figure 6

Comparative HOMO and LUMO graphical representation 


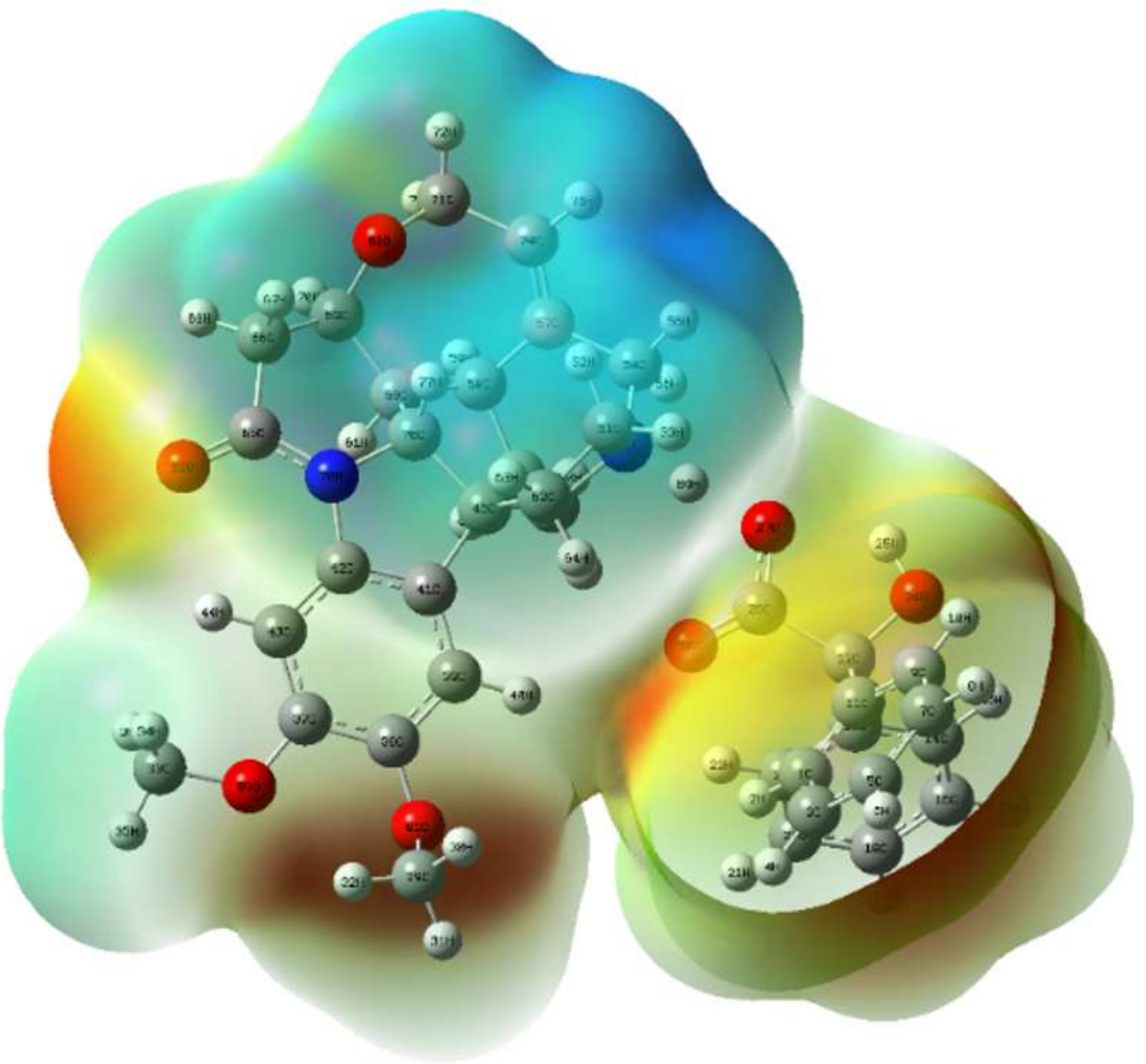

Figure 7

Molecular electrostatic potential maps of brucinium benzilate 


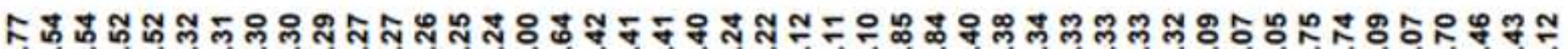

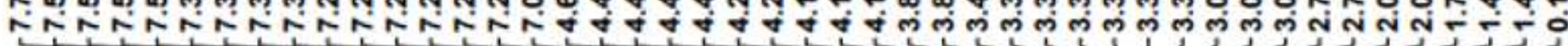

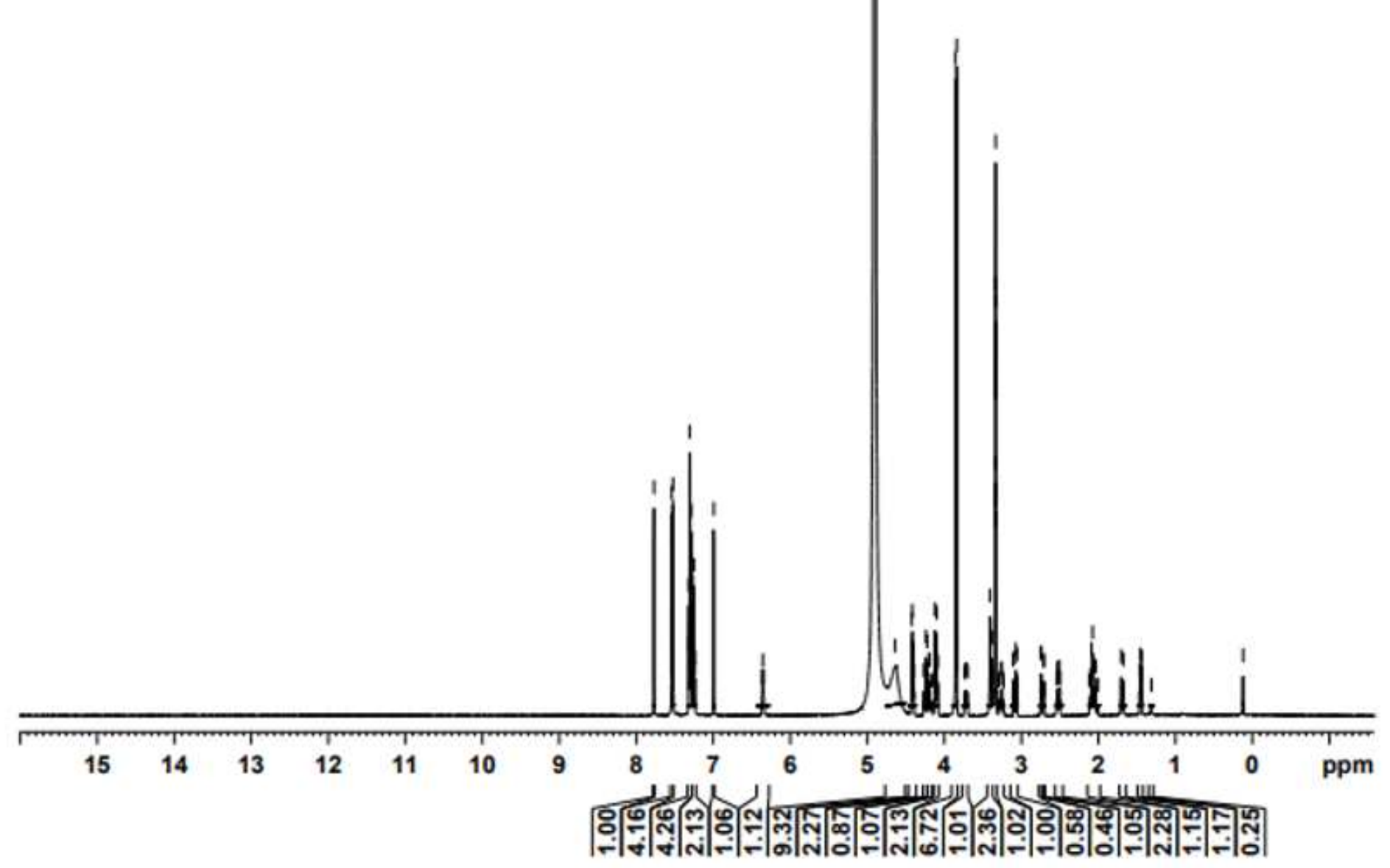

Figure 8

$1 \mathrm{H}$ NMR spectrum of BBA in MeOD 


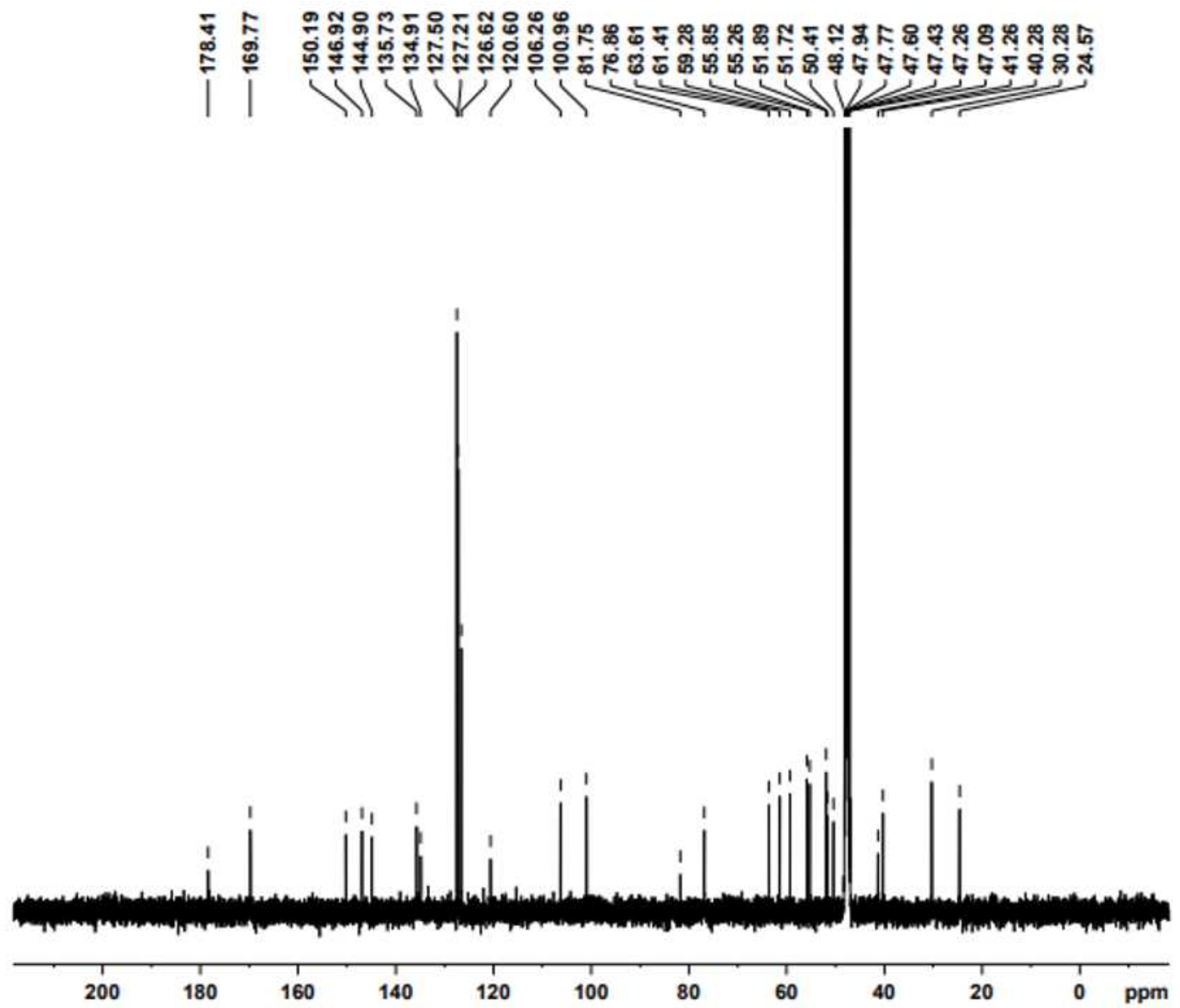

Figure 9

13C NMR spectrum of BBA in MeOD 


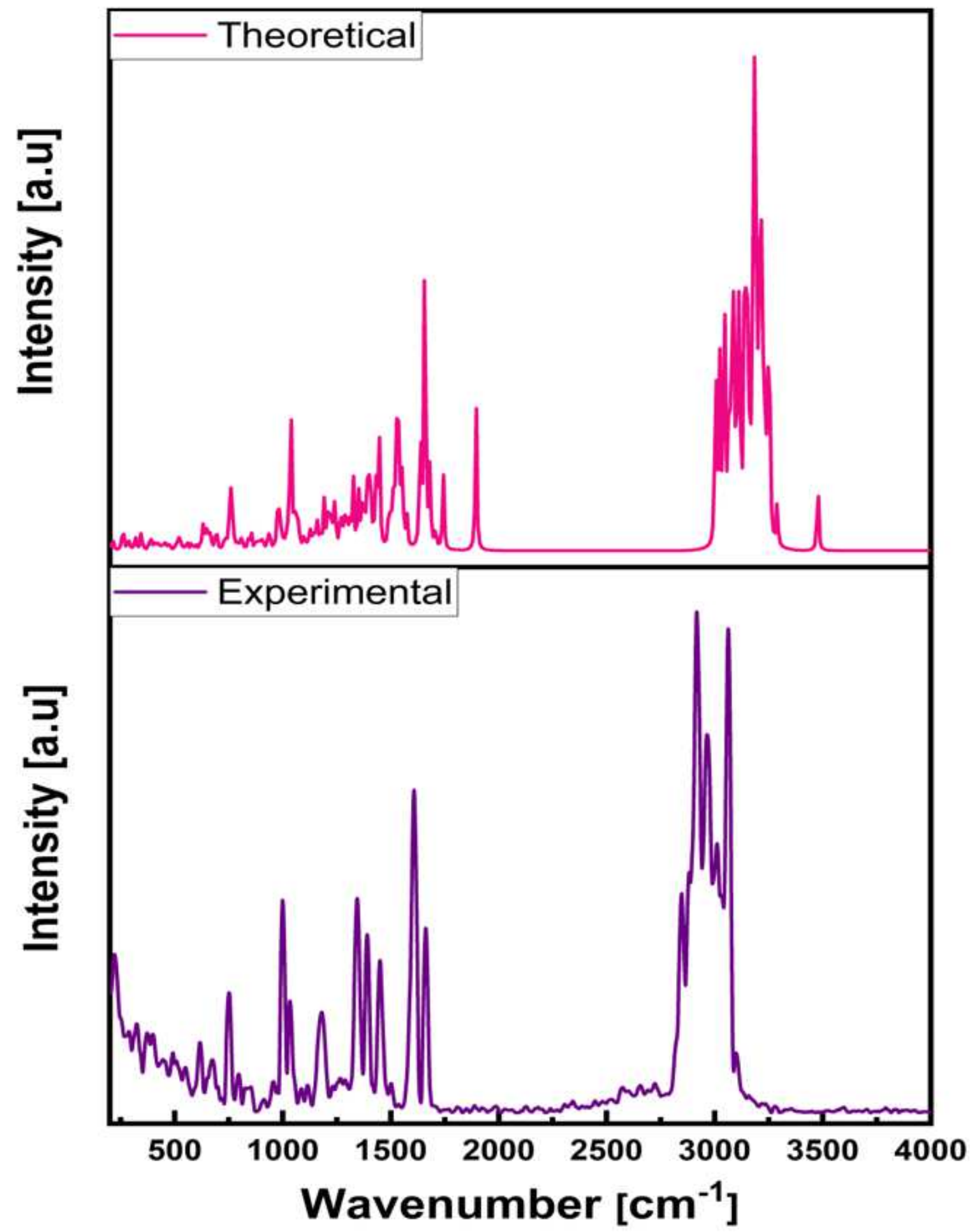

Figure 10

Experimental and theoretical ATR-IR spectrum 


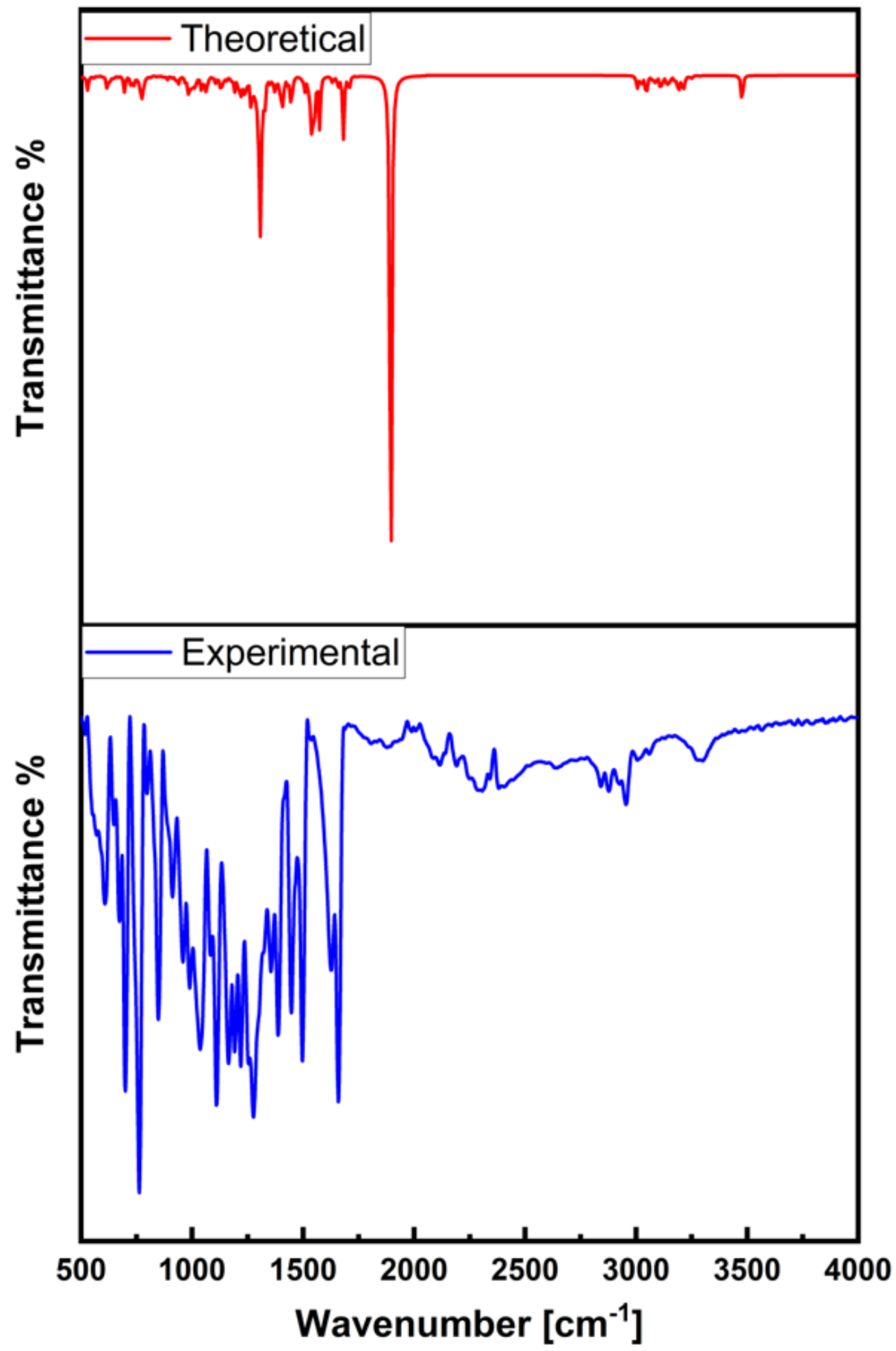

Figure 11

Experimental and theoretical Raman spectrum 

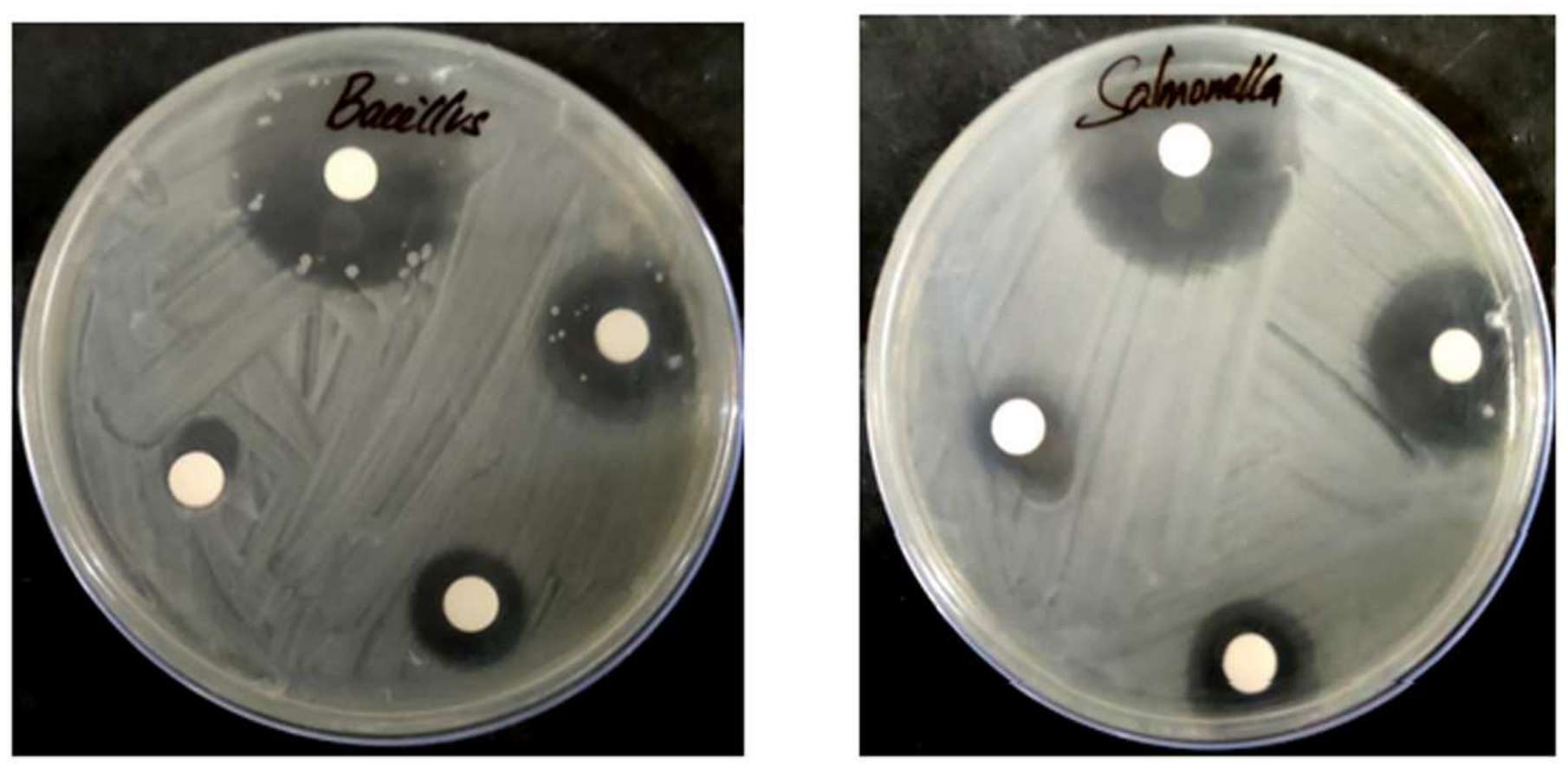

Figure 12

Photograph of Antibacterial activities

\section{Supplementary Files}

This is a list of supplementary files associated with this preprint. Click to download.

- Supplementary.docx 